KLAUS S. LACKNER

Columbia University

JEFFREY D. SACHS

Columbia University

\title{
A Robust Strategy for Sustainable Energy
}

ONCE AGAIN THE debate has intensified over whether energy as a commodity is running out. Just six or seven years ago the world seemed awash in oil, yet today many pundits predict the end of oil and indeed the end of the fossil-fuel era. ${ }^{1}$ With its recent merger with the California-based oil company Unocal, Chevron has placed a bet on ever-increasing oil prices. ${ }^{2}$ Two other oil giants, BP and ExxonMobil, on the other hand, have publicly stated that resources appear plentiful. ${ }^{3}$

Even if the world's oil resources are indeed plentiful, world energy supply remains very much constrained. As a world population headed toward 9 billion strives for a standard of living that the industrialized nations take for granted, energy demand will increase rapidly, straining the entire supply chain from exploration to refining. To complicate matters further, oil and gas resources are concentrated in a small region of the world, leading to a more fragile and more volatile trading system that shows strong monopolistic tendencies. In addition to all of this, environmental concerns pose perhaps the toughest constraint of all.

1. See the cover article ("Drowning in Oil") and further extensive discussion of an oil glut in The Economist, March 4, 1999, which predicts an oil price of \$5 a barrel. Deffeyes's book on Hubbert's peak (2001) is a good example of many that currently foresee the end of the oil era. Goodstein (2004) is particularly pessimistic, suggesting that oil is running out and that other fossil fuels make unlikely substitutes.

2. See R. Gold, "Reserve Judgment: In Deal for Unocal, Chevron Gambles On High Oil Prices," Wall Street Journal, August 10, 2005, p. A1.

3. See BP's Statistical Review of World Energy (BP, 2005), which sees oil reserves growing in absolute terms, in spite of a drastic increase in oil demand. ExxonMobil's "The Outlook for Energy" (ExxonMobil, 2005) states that large oil resources still exist. 
Forecasts of future energy consumption and of trends in energy infrastructure development are fraught with enormous uncertainties. ${ }^{4}$ Strategies for long-term energy planning must be robust to unpredictable variations in the dynamics of world development. This paper develops robust strategies for maintaining economic growth and worldwide development while overcoming shortages in some of the raw resources, as well as supply constraints due to environmental concerns, that threaten to block access to most conventional energy sources.

The paper will make the case that the known energy resource base is more than sufficient to provide a growing world population with energy on the scale to which the industrial countries have grown accustomed and to which the developing countries now aspire-but only if far-sighted investments are undertaken in a timely way. Environmental constraints will be more difficult to overcome, but they, too, have promising solutions, and again a long lead time will be needed. The key to both the supply-side and the environmental concerns will be the timeliness with which decisions are made.

Today's technology base is insufficient to provide clean and plentiful energy for 9 billion people. To satisfy tomorrow's energy needs, it will not be enough simply to apply current best practices. Instead, new technologies, especially carbon capture and sequestration (CCS) at large industrial plants, will need to be brought to maturity. Fortunately, CCS and certain other needed technologies are already in early implementation. However, without substantial progress in the way energy is found, transformed, and transported, the world will indeed run into a severe energy crisis.

The main arguments of the paper can be stated as follows:

- The use of large quantities of energy is central to the functioning of an advanced economy. There are severe limits to energy conservation even in the long run. Global economic growth will bring about significant increases in primary energy demand.

-Energy resources are fungible, especially among the fossil fuels. For example, coal can be converted into liquid fuels such as gasoline at low cost. So, too, can other, nonconventional fossil fuels like oil sands and shale and potentially the methane hydrates that are abundant on the sea floor. Noncarbon energy sources such as nuclear and solar energy could

4. See the enormous range of predictions summarized in the report of the Intergovernmental Panel on Climate Change on scenarios (Nakicenovic and others, 2001). 
each provide a substantial fraction of the world's long-term energy needs, but both present problems in the short term.

- There are no serious long-term (century-scale) shortages of fossilfuel supply once the interconvertibility of oil and other fossil fuels is taken into account. Even the arrival of "peak oil" - the point at which oil production reaches a maximum-would not mean a global energy shortage at today's prices. However, the transition from oil to other sources of liquid fuel will require a significant lead time, and engineering that transition should be part of public policy.

- The greater constraints are likely to emerge from environmental concerns, especially the rising concentration of atmospheric carbon dioxide $\left(\mathrm{CO}_{2}\right)$ acting as a greenhouse gas. Carbon emissions will have to be mitigated, because the business-as-usual course is fraught with grave global risks. The limits on the global oil supply will not reduce the risks from $\mathrm{CO}_{2}$, since coal and other low-cost fossil fuels will in any event substitute for declining supplies of petroleum and natural gas, and their $\mathrm{CO}_{2}$ emissions will be larger, not smaller.

- Realistic technologies that can mitigate the carbon challenge up to the middle of this century at modest cost are nearly ready for application. The centerpiece of such a strategy will most likely be CCS at power plants and other large industrial units such as steel and cement factories. The cost of implementing these technologies on a large scale is likely to be below 1 percent of gross world product if they are carried out with a long lead time. In addition to CCS, conversion of the vehicle fleet to hybrid or other lower-carbon technologies is very likely to be cost effective and might well pay for itself.

-An extension of these technologies to implementations that are more exotic but still highly plausible could further reduce emissions in the second half of the century and lead to an energy infrastructure that, by the end of the century, could produce zero net emissions of carbon into the environment.

- These transitions will have to be implemented worldwide, and this will put financial pressure on today's low-income countries. Equity considerations will suggest that the rich countries bear a significant cost of the carbon management that must be introduced in low-income settings.

-On a century-long time scale, the world's current energy technologies are inadequate. Even with a CCS strategy and vast improvements of energy efficiency in transport, continued economic growth will tend to 
push atmospheric carbon concentrations well above prudent levels. Thus fundamental research into new, decarbonized energy systems is needed, alongside the more practical steps mentioned above in the first half of the century.

\section{The Role of Energy in the World Economy}

Technology in general and energy at its base ultimately define the carrying capacity of the Earth for humans. Today's population densities far exceed what could be maintained by natural means. Given the physical size of the human body and empirically observed scaling laws governing animal population densities, the biologically supportable population density for humans should be about 3 per square kilometer. ${ }^{5}$ The fact that human populations far transcend this number is surely related to humankind's ability to provide energy far in excess of human metabolic power. Just one pertinent example is the energy used to produce nitrogenbased fertilizers, which have played a decisive role in the rise of food production in the past century. ${ }^{6}$

The amount of primary energy that the average American or European consumes today is roughly 100 times his or her metabolic power. With a population density about 100 times the expected natural level, and energy consumption about 100 times the metabolic level, Europeans and Americans enter the ecological system with a power consumption per unit area that exceeds that of other species by about four orders of magnitude. ${ }^{7}$ Maintenance of such an elevated carrying capacity requires continued access to readily available energy.

5. Damuth (1991) develops scaling laws for the maximum population density and metabolic energy demand of animals as a function of their body weight.

6. See the review by Smil (2001).

7. This follows from the scaling laws for population density and metabolic energy consumption found by Damuth (1991). The scaling laws indicate that power consumption per unit area of land is the same for all species. Based on a caloric input of 2,000 kcal a day, or $100 \mathrm{~W}$, for human metabolic energy demand, and a U.S. primary energy use of $10,000 \mathrm{~W}$ per capita (Energy Information Administration data), the ratio of commercial to metabolic energy consumption is about 100 . Population densities in urbanized regions are typically several hundred people per square kilometer (that of the state of New Jersey is 437 per square kilometer, according to the U.S. Census Bureau), hence the second factor of 100 . 
Energy consumption is unavoidable in maintaining an organized state away from thermodynamic equilibrium: dissipation of energy will eventually cause such a system to disintegrate unless energy is allowed to flow through it. Any highly organized society will therefore consume a large amount of energy. How much energy depends on the activities the society pursues. A society that relies on intensive travel, for example, will require more energy than one that uses telecommunications for most interactions. Energy consumption patterns also will depend on the ability to minimize energy dissipation rather than compensate for it with additional energy. This is the role of improving energy efficiency.

World primary energy consumption today is about 14 terawatts (TW), or about 2.2 kilowatts $(\mathrm{kW})$ per person. The United States consumes about $11 \mathrm{~kW}$ per person, whereas in the poorest countries the consumption of commercial energy is not much different from the human metabolic output of about $100 \mathrm{~W}$ (figure 1). About 85 percent of all commercial energy consumed in the United States today is derived from fossil fuels. Annual U.S. consumption of carbon amounts to roughly 5.5 tons per person, or 1.6 billion tons (that is, 1.6 gigatons of carbon, or GtC) in total. ${ }^{8}$ Annual world consumption is $6.8 \mathrm{GtC} .{ }^{9}$

If the whole world consumed carbon at the U.S. per capita rate, carbon consumption and carbon emissions would be more than six times higher than they are. This greater use would not only exhaust the available oil by the end of this century (and perhaps sooner) but also threaten massive environmental damage. The key energy challenge is thus to accommodate rising energy demand, as part of global economic development, within the constraints on oil and climate.

Solar energy is by far the largest ultimate source of energy available for human use (other sources include geothermal and fission power). The Earth intercepts $170,000 \mathrm{TW}$ of power from the sun; ${ }^{10}$ this solar flux exceeds human primary energy consumption by some four orders of magnitude. ${ }^{11}$ Biological systems-plants—capture via photosynthesis less

8. This figure is based on $\mathrm{CO}_{2}$ emissions data and population data from the Energy Information Administration (2005b).

9. Energy Information Administration data for 2003.

10. Based on handbook values for the solar energy flux near the Earth's orbit of $1,370 \mathrm{~W} / \mathrm{m}^{2}$ and the Earth's radius of $6,370 \mathrm{~km}$.

11. Based on data published by the Energy Information Administration. 
Figure 1. Primary Energy Consumption and Gross Domestic Product

$\mathrm{kW}$ per capita ${ }^{\mathrm{a}}$

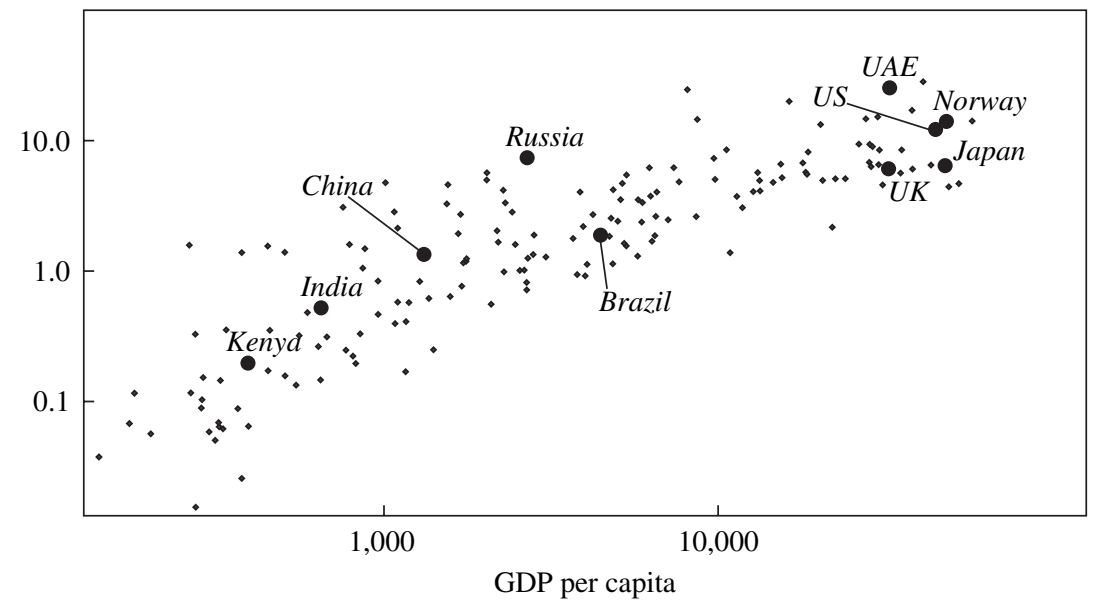

Source: Data from EIA (2002).

a. Scales on both axes are logarithmic.

than 0.1 percent of this energy (100 GtC equivalent, ${ }^{12}$ or about $130 \mathrm{TW}$ ) and convert it into chemical energy. Although most of this energy is used by the plants themselves, a small fraction of energy-containing biomass remains to be consumed by animals and humans as a metabolic energy source, and by humans to generate heat or electric power through nonmetabolic combustion. Solar energy is also the ultimate source of fossil fuels, which are the fossilized remains of energy accumulated through photosynthesis in geological time, as well as the source of wind power (about 200 TW worldwide) and hydropower (driven by solar-powered water evaporation and precipitation in the planet's hydrologic cycle).

Harnessing a much larger proportion of the solar flux for commercial energy use, for example through photovoltaic conversion to electricity, is very likely to be the main long-term, low-cost solution to the problem of supplying sustainable, renewable energy (with nuclear power a possible long-term alternative). However, most forms of solar power are still too

12. For the overall production of carbon bound by photosynthesis, see, for example, the Schimel and others (1995) reviews discussing the natural carbon cycle. The conversion to power equivalent is based on a rough estimate of the energy stored in biomass of 500 kilojoules per mole of carbon. 
costly to provide plentiful, abundant, low-cost energy on the scale of current fossil-fuel use. A major, if not the major, energy challenge over the coming decades is to bring down the cost of solar energy. In the meantime, access to fossil energy must be maintained.

\section{Substitution among Energy Sources and Carriers}

The various forms of energy are very much interchangeable. Oil, coal, and gas are nearly completely fungible, and the conversion of one form into the others adds comparatively little cost. SASOL, a South African energy company, converts that country's coal into gasoline and diesel at prices competitive with crude oil at about $\$ 35$ to $\$ 50$ a barrel (less than the cost of crude at current prices as of this writing), ${ }^{13}$ using a method known as the Fischer-Tropsch process. Some engineering studies today suggest that this conversion could be done at even lower cost. ${ }^{14}$

The input to the Fischer-Tropsch process is synthesis gas, a mixture of carbon monoxide and hydrogen. The hydrogen reacts with the carbon and oxygen to form liquid hydrocarbons and water. Products range from methanol to alkane chains such as octane and decane (the constituents of gasoline and diesel fuel) to paraffin waxes, the specific product being largely determined by pressure and temperature conditions during the reaction and by the choice of catalysts. Synthesis gas can be produced from virtually any carbonaceous input stream. It can be the result of partial oxidation and steam reforming of natural gas, but it also can be produced in the gasification of coal (as by SASOL) or of biomass. It can also be used in the production of other chemicals.

If oil were to run out, the liquefaction of coal would be an obvious candidate for filling the gap, as would conversion of tar to synthetic crude oil.

13. The true price of synthetic oil can only be estimated. Lumpkin (1988), without ever mentioning the successful implementations in South Africa, claimed that the state-of-the-art price at that time was $\$ 35$ a barrel. SASOL plants still produce 30 percent of South Africa's transportation fuel and are making money without government support. In 1999 SASOL estimated the cost of a barrel of its product at about $\$ 18$, excluding capital expenditure (Kaneko and others, 2002). Capital costs are high, however; they have been estimated at $\$ 30,000$ for the capacity to produce one barrel a day (Kirk-Othmer Encyclopedia of Chemical Technology, 2000, article on "Fuels"). At a 20 percent annual cost of capital repayment, this would add $\$ 16$ to the price of a barrel.

14. See, for example, Steynberg and others (1999). 
Another option would be to liquefy natural gas or methane obtained from methane hydrates. Moving from the handful of coal-to-liquid plants that have been built so far to the thousands of plants necessary to replace oil would very likely cause a significant drop in the unit cost but would require a long lead time. Past experience suggests that it would be very surprising if the cost did not come down by at least a factor of two under such conditions. Therefore the long-term price of liquid hydrocarbon fuels may be lower than it is today, even allowing for pessimistic forecasts for oil and gas reserves. Even with the most conservative assumptions about learning curves, it appears quite safe to predict that the cost of synthetic oil from coal or other processes, after some transitional pains, will be below $\$ 30$ a barrel.

Although the abundance of coal reserves and the existence of low-cost processes for transforming coal set a ceiling on the likely long-term cost of oil-like hydrocarbons, this does not guarantee that future development will actually gravitate to coal. It is possible that oil and natural gas will not run out after all, or that other options such as tar sands and oil shales will prove more competitive. Tar sands in particular have proved competitive at oil prices below $\$ 30$ a barrel, but it will take time to build up the necessary capacity. ${ }^{15}$ Although they are not yet competitive, methane hydrates found under the Arctic permafrost and, more important, on the ocean floor could potentially provide a virtually unlimited source of methane.

Substitution away from fossil carbon altogether could also happen. Nuclear energy can already provide competitively priced electricity. Wind and solar energy could add to this pool. Biomass carbon could replace at least some fossil fuels, for example in the transportation sector, using in effect the same technologies that allow the substitution between various fossil fuels.

Just as different energy resources can substitute for each other, so, too, can different energy carriers also compete with each other. The dominant carrier today is electricity, followed by liquid fuels (gasoline, diesel fuel, and jet fuel) for the transportation sector and gaseous fuels (natural gas, and to a limited extent manufactured gas, or "town gas") for industrial uses and for the residential and commercial heating sector. Solid fuels play a much smaller role as energy carriers. Their usefulness seems to be lim-

15. On the economics of tar sands see, for example, National Energy Board, Canada (2004). 
ited to certain industries, such as steel production and cement manufacture, and to the generation of electricity. ${ }^{16} \mathrm{~A}$ small amount of energy is brought to the consumer directly as heat.

There are limits to substitution among carriers, however. Electricity usually requires wires and thus is most suitable for stationary applications. Heat pumps are not cost effective enough to allow electricity to replace chemical fuels for space heating, although they do well for space cooling. With heat pumps, electricity could provide low-grade heat more efficiently than the combustion of chemical fuels. Transmitting electricity via microwaves has been discussed in the past, ${ }^{17}$ but it has not found a foothold in today's economy. An interesting possible application of such a technology may be the short-distance transmission of power from a roadbed to vehicles. Of course, it is not impossible to use wired electricity in the transportation sector-witness its use in railroad systems around the world. Although the idea seems futuristic, there is no obvious reason why automobiles could not be driven with externally provided electricity, and if hybrid gasoline-electric automobiles prove to be a real success, they may offer an effective means of combining an external electric charge (through plug-ins at home or recharge from the roadbed) with battery storage on board the vehicle.

Other substitutions rely not on substituting one form of energy for another but on replacing energy consumption with other alternatives. A large fraction of efficiency improvements ultimately fall into this category. Greater investment in the energy-efficient design of automobiles, for example, is a way of reducing their emissions. By using computers to optimize route planning and clever pricing algorithms to minimize unsold seats, the airline industry can reduce total miles flown, or increase passenger-miles flown for a given amount of fuel, and thus reduce energy consumption.

Higher energy prices also reduce consumption. But the price elasticity of demand for primary energy seems surprisingly small, typically estimated in the range of -0.1 to -0.5 in the long run, and closer to -0.1 in the short run. ${ }^{18}$ It is difficult to find substitutes for energy, and cost-effective

16. Steel production accounts for about 6 percent of world $\mathrm{CO}_{2}$ emissions (Hidalgo and others, 2005), and cement manufacture about 5 percent (Worrell and others, 2001). In the United States, coal-fired electric power plants are responsible for 31 percent of all $\mathrm{CO}_{2}$ emissions, according to the Energy Information Administration (2004a).

17. Brown (1984).

18. See the studies by Dahl $(1992,1993)$. 
options for increasing energy efficiency are more limited than is often suggested.

\section{Limitations on Energy Supply}

In recent years much has been made about the possibility of the world's energy resources running out. This concern arises, however, from mistaking oil and natural gas for all primary energy. Although these may run out relatively soon, the world's total energy resources will last far longer. In particular, the vast reserves of coal and coal-like resources ensure that hydrocarbon fuels in their various forms-solid, liquid, and gas-will be in plentiful supply, at today's prices or less, over a century-long horizon and more. ${ }^{19}$

\section{Oil and Natural Gas}

Crude oil is today probably the world's most intensively utilized energy resource and thus may indeed be the first to be exhausted. Indications that oil reserves are gradually being depleted can be found in a general trend toward smaller and more remote oil fields producing lower-quality oil. ${ }^{20}$ On the other hand, according to the BP annual survey, ${ }^{21}$ total proven reserves have grown steadily over the last twenty years, and the ratio of proven reserves to annual production has risen from about 30 in 1984 to 40 in 2004. Even at current high prices, which indicate supply bottlenecks, proven reserves held steady in 2004. The reserves-to-production ratio, however, dropped because of a significant increase in demand.

Is oil production near its peak, as some observers claim? Assuming a logistic curve for the extraction of oil, maximum production will be reached when half of the oil has been consumed. Based on this logic, M. King Hubbert in 1956 correctly predicted that oil production in the continental United States would peak in the early 1970s. ${ }^{22}$ Since worldwide proven reserves today appear to be comparable in size to all the oil

19. Rogner (1997) shows that proven reserves of coal alone exceed what would be required for the twenty-first century.

20. See Deffeyes (2001).

21. BP (2005).

22. Hubbert (1956). 
that has been consumed, it has been argued that the peak of global oil production should be near. ${ }^{23}$

There is, however, a risk of circular reasoning in estimating the oil peak, which comes down to the meaning of "proven reserves." To a large extent, proven reserves are those reserves that oil companies have chosen to put on their books as long-term inventory. If this inventory stock is kept proportional to expected sales, as it must be if it is the minimum amount needed to support current rates of extraction, then the ratio of proven reserves to consumption will be a constant, as indeed it has been, more or less, over the last thirty years. Since historical consumption is well represented by an exponential growth rate, the amount of oil that has already been consumed is also a constant multiple of current consumption. As a result, Hubbert's peak will always appear to lie a fixed time from the present, and, given that the two time constants are comparable, Hubbert's peak will always seem near.

\section{Physical Limits of Oil Production}

Estimates of the world's total oil resources are hotly debated. Contrast, for example, the view of Matthew Simmons with that of Hans-Holger Rogner. ${ }^{24}$ Simmons claims that much of the vast Saudi reserve is not really available for extraction. Rogner accepts that proven reserves in 1996 amounted to about forty years of current production (150 Gt of oil equivalent, in rough agreement with the BP report) but adds to this a nearly equal amount of probable (61 Gt of oil equivalent) and speculative resources (84 Gt of oil equivalent), plus another comparable amount available through enhanced recovery (138 Gt of oil equivalent). Resources in tars and shales add another $380 \mathrm{Gt}$ to the total.

There are indeed signs of depletion. The discovery of truly large reservoirs has effectively halted, and, since an enormous peak in the 1960s, rates of discovery have not even come close to what they were then. However, these discoveries reflect nearly incidental additions to the Middle East reserves, which to this day have not been worked down. When these fields seemed effectively inaccessible, during the oil embargo, smaller but more numerous fields elsewhere took their place. Sometime in the 1970s, 
oil moved into a regime in which reserves added through exploration just kept up with inventory maintenance. Before then, oil, just like coal today, enjoyed inventory additions in excess of inventory demands. Today, in contrast, exploration has to systematically scour the entire planet for oil and gas to be added to the resource pool. Based on the available data, reliable predictions of future reserves of oil are virtually impossible.

A robust global energy strategy should not and need not rely on oil. It should, however, be able to accommodate both oil and natural gas, if supplies turn out to last longer than expected. One possible scenario is that oil resources will remain more or less steady as improved production techniques keep up with a gradual depletion. However, this outcome would be barely distinguishable from another in which oil sands, coals, and lignites (brown coal) make up for an apparent shortfall in oil and gas.

\section{The Geographic Concentration of Oil and Gas}

The challenge in supplying oil and natural gas derives not only from the depletion of their reserves but also from their uneven worldwide distribution. By far the greater part of today's proven reserves of oil lie concentrated in a relatively small region of the world. Countries in this region, by virtue of this extremely skewed distribution, are afforded a substantial amount of pricing power. Moreover, nearly all the oil produced in the world is ultimately funneled through a small number of big oil companies, which, just like the oil-producing countries, have a vested interest in maintaining a high oil price.

This pricing power is further amplified by the fact that the energy sector tends to operate with large plants that require huge investments in nearly permanent structures. The result is a high cost of entry into the market. Thus a major challenge in approaching low-cost fossil energy systems is how to encourage competition. Developing alternative resources would strengthen this approach. Reducing the dependence on large plants would help in creating competition.

\section{Coal and Nonconventional Fossil Fuels}

When one looks at all fossil fuels in the aggregate, however, the resource picture changes dramatically. Unlike in the case of oil, where proven reserves in effect seem to act like an inventory, the reserve situation in coal is more akin to the special case of the Saudi oil fields. Because 
the amount of coal already known to exist would last for more than a century even under rapid-growth scenarios, coal exploration is not a worthwhile activity at present.

Coal alone could satisfy the energy needs of the twenty-first century; indeed, at the price of a greater challenge to environmental mitigation, coal could act as a viable safety net in the energy sector. As already discussed, coal can be transformed to synthetic oil via Fischer-Tropsch reactions. Moreover, lignites and other low-grade coals, which exist in even greater supply than high-grade coals, are well suited for generating synthetic fuels. This matters in Germany, for example, where high-grade coal is in short supply but low-grade brown coal is available in vast quantities-about 230 years at current rates of production. ${ }^{25}$

Oil shale resources are also very large, but no process yet exists for extracting oil from these shales cost-effectively, although improved processes are suggested occasionally. It appears that oil shales could compete with crude oil somewhere between $\$ 30$ and $\$ 100$ per barrel of oil equivalent. ${ }^{26}$ Development of new technology, just as in the case of the tar sands discussed below, could drastically lower this number. The current difference in price between the two energy resources may be due at least in part to a history of more determined government support in Canada for tar sands.

Tar sands represent a huge resource base and are already starting to enter the market. The Canadian tar sands are comparable in energy content to the Saudi oil fields and are at least matched by resources known to exist in Venezuela. Canadian synthetic oil from tar is already starting to play a major role in Canada's oil supply. ${ }^{27}$

Whether or not these low-grade energy resources come to be used extensively over the next century will in large part depend on the actual

25. Based on information from the trade association of the German lignite industry, Bundesverband Braunkohle (www.braunkohle.de). The site claims that 41 billion tons exist in reserve, compared with annual production of 182 million tons. The size of the resource is confirmed by information provided by the German Foreign Office (www.tatsachen-ueberdeutschland.de).

26. A recent RAND study (Bartis and others, 2005) claims that inflating costs from past projects of shale extraction leads to cost estimates between $\$ 75$ and $\$ 95$ per barrel equivalent. In situ extraction schemes may have much lower costs, possibly below $\$ 30$, but these technologies have not been proven yet.

27. See the National Energy Board report on Canada's oil sands (National Energy Board, Canada, 2004). 
availability of oil and natural gas. It is quite possible that, despite the pessimistic outlook held by some today, the available natural gas resources will prove sufficient to supply the energy needs of a burgeoning world population for decades to come. What would then be required is a way of shipping this fuel cost-effectively around the world. Over the next fifty years, methane hydrate extraction may also begin in earnest. If this were to prove cheaper than coal or lignite processing, the world would not need to move to low-grade hydrocarbons but instead would utilize these relatively clean fossil carbon resources. In any case, fossil fuels, whether high grade or low grade, are likely to provide a long-run energy backstop, through this century and into the next, at a price of perhaps $\$ 50$ a barrel or conceivably even less (assuming, as discussed below, that CCS is feasible at modest cost).

In summary, the vast resource base in fossil fuels suggests that they can dominate the world's energy supply into the twenty-second century. Figure 2 shows how the production cost of fossil energy would stay affordable until cumulative fossil-fuel consumption exceeds its present value by about a factor of 15. Even allowing for the large uncertainty in such predictions, predicting the impending demise of fossil fuels is premature.

Figure 2. Extraction Cost of Carbon as a Function of Cumulative Consumption

Constant 2000 dollars per barrel of oil equivalent

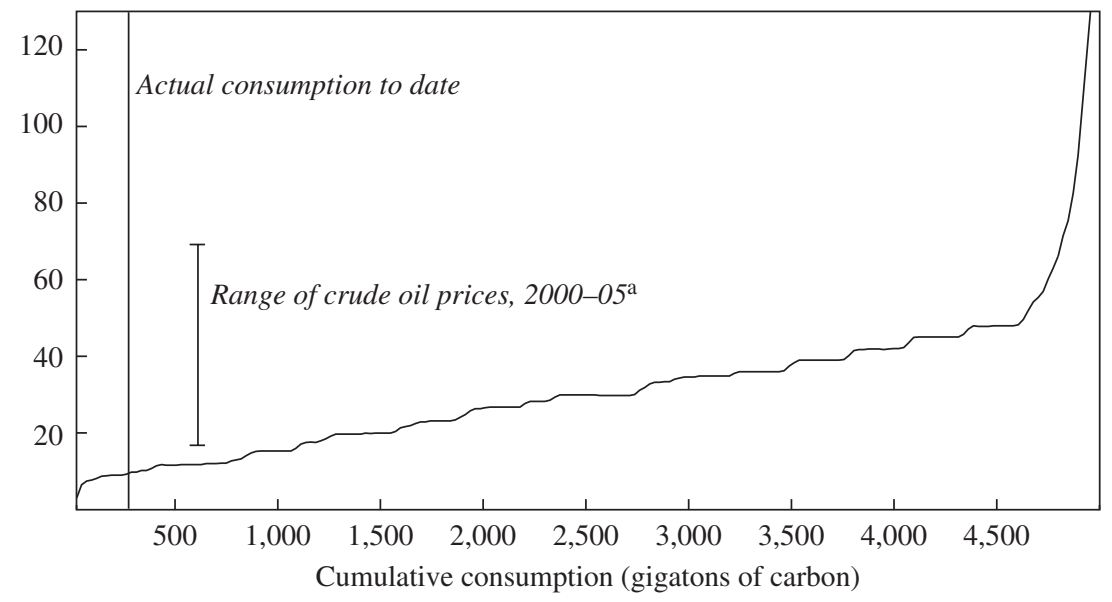

Source: Authors' calculations using data from Rogner (1997, figure 8) and the Energy Information Administration. a. In current dollars, through November 2005 . 
Although we do not predict an immediate move toward coal, the long-term fossil energy base is dominated by coal, unless usable methane hydrate sources prove even bigger.

\section{Limits to Renewable and Nuclear Energy}

Nonfossil energy sources-hydropower, waves, tides, wind, geothermal, nuclear, and solar - are all potentially important, but they are unlikely to replace the need for massive and growing use of fossil fuels for decades to come. In some cases (hydro, waves, tides, geothermal) the scale of the energy source itself is physically limited. In the case of nuclear energy the limits are mainly related to safety (the risks of nuclear proliferation). In the case of solar the principal constraint is cost. The following is a very brief summary.

Hydroelectricity is a large source of cheap power, but it cannot by itself satisfy the world's energy market. As an illustration, given average altitude and rainfall, one can estimate for the United States-already an important producer of hydropower-the theoretical limit of energy that could be extracted, simply by calculating the potential energy in estimated rainfall. At typical rates of precipitation, the maximum hydropotential is about $140 \mathrm{GW}$, which is less than the total electricity the United States produces today. ${ }^{28}$ Actual implementation will fall far short of this ambitious limit: data from the U.S. Energy Information Administration (EIA) indicate that about 20 percent is utilized. And in any case the construction of hydroelectric dams in the United States has effectively halted.

Just like hydropower, waves, tides, and ocean currents, whether singly or combined, cannot supply all of human energy demand..$^{29}$ Indeed, these sources cannot be relied on to supply even a large fraction of future human energy consumption, although in some regions they may represent the low-cost solution.

Wind energy systems are approaching the low costs necessary to be a serious competitor in world energy markets. However, current world energy consumption already represents a substantial fraction of all the

28. For a calculation of this number see Howes and Fainberg (1991). The result makes clear that hydroelectricity is unable to satisfy the world's energy demand.

29. Falnes and Lovseth (1991); Munk (1997). 
energy invested by the sun in driving the global wind field..$^{30}$ Meanwhile energy consumption is expected to quadruple or more during the century, and it is difficult to see how one could extract 10 to 20 percent of the power that drives the wind without having a substantial impact on climate. $^{31}$

Nuclear energy today provides about 18 percent of the world's electricity supply, according to the EIA. It is used nearly exclusively to generate electricity, although in principle it could also be used to provide heat. The potential for nuclear energy is large, but current estimates of accessible world uranium resources are too small to support a world energy infrastructure predominantly based on conventional (that is, nonbreeder) nuclear power. ${ }^{32}$ It has been suggested that the uranium in seawater could make up the difference, but the sheer volume of seawater that would have to be filtered raises once again questions of environmental viability. ${ }^{33}$

An alternative would be to move toward breeder reactors based on either uranium-238 or thorium-232; such reactors create additional fuel in the process of their operation. This would increase the supply of fuel by about two orders of magnitude and thus remove all century-scale concerns over resource limitations. ${ }^{34}$ However, to maintain a sufficient supply of fuel while expanding nuclear electricity production, the world would have to embark on a major breeder reactor program soon, or at the very

30. To provide all of current primary energy consumption in the United States from wind energy would require capturing, every day, all the kinetic energy from wind over an area of about $500 \mathrm{~km}$ by $500 \mathrm{~km}$. Meeting world energy consumption would require almost four times that area. This calculation is based on the total kinetic energy in the atmosphere, which is about 1.3 megajoules per square meter (Houghton, 2001); and total primary energy consumption, which is about 4 TW for the United States and about 14 TW for the world, according to the EIA.

31. This impact has been pointed out by Keith and others (2004).

32. Hoffert and others (2002) point out that the world's proven uranium resources would be depleted in a matter of a few decades if all energy were to be supplied by conventional uranium-based reactors.

33. Current consumption of uranium (approximately 70,000 tons a year; Uranium Committee, 2005) would require processing nearly a million cubic meters of seawater per second to collect 65 percent of the $3 \mathrm{mg}$ of uranium present in each cubic meter; this would mean intercepting a flow of water roughly equivalent to the Gulf Stream at the Strait of Florida. A world reliant on nuclear energy could easily consume 30 times as much uranium (Stewart, 2005). Intercepting a flow of that magnitude would clearly have environmental consequences.

34. See, for example, Hoffert and others (2002). 
least store the waste from conventional reactors in such a way that it could be recovered and reprocessed later. In addition, the risk of proliferation of fissile materials suitable for use in nuclear weapons is widely seen today as a binding technical and political constraint. Breeder technologies create such materials and thus exacerbate this risk.

In summary, nuclear technology, although somewhat constrained in its development by the availability of uranium-235, is not fundamentally constrained by resource limits, provided one opens the door to breeder programs. Any fusion-based energy technology would be completely unlimited by resource constraints, and the proliferation risks and waste management problems would also be significantly less. However, so far fusion energy has remained only a theoretical possibility.

Geothermal heat is another primary energy source. Heat reservoirs underground and in the ocean are very large. However, installations designed to tap these reservoirs would in most cases have to operate on very small temperature differences, which implies high costs and large machinery. Only a few parts of the world, such as Iceland, have highgrade geothermal heat sources. Geothermal energy can thus be a very effective niche player where there are large temperature gradients, but it is not likely to provide the bulk of the energy required to run a growing world economy. ${ }^{35}$

Solar energy, unlike the other renewable energy resources described, is virtually unlimited in scope. The average energy of sunlight falling on a square meter of the Earth's surface is about $300 \mathrm{~W} .{ }^{36}$ (This figure averages across day and night, but it assumes a clear sky and dry air.) Realistic estimates of how much of this energy could actually be captured are somewhat smaller, but still far exceed current energy consumption. A 1 -million- $\mathrm{km}^{2}$ field of solar panels (an area equivalent to 10 percent of the Sahara) would, at 10 percent efficiency, collect approximately twice current world energy consumption. ${ }^{37}$ At an efficiency of 15 percent,

35. For a good discussion of geothermal energy see Howes and Fainberg (1991).

36. Since the surface of a sphere is four times its cross section, the average incoming flux is $340 \mathrm{~W} / \mathrm{m}^{2}$. Allowing for the Earth's albedo, the flux reaching the ground is slightly lower, and it depends on the latitude of the site. For details see handbook data (for example, the CRC Handbook). An average number for latitudes around $30^{\circ}$ is $300 \mathrm{~W} / \mathrm{m}^{2}$. Weather will further reduce this number, even in a desert, to about $200 \mathrm{~W} / \mathrm{m}^{2}$. (See, for example, Howes and Fainberg, 1991.)

37. These calculations are based on a time-averaged collection efficiency of $30 \mathrm{~W} / \mathrm{m}^{2}$. 
about half the average electricity generated in the United States could be produced within the boundaries of the White Sands Missile Range in New Mexico. ${ }^{38}$

There is thus no shortage of solar energy. The problem is cost. At present, solar energy is far too expensive to be more than a niche player in the world's energy infrastructure. The cost of solar energy is about $\$ 4$ per peak watt installed; ${ }^{39}$ in a sunny climate this translates into roughly $\$ 16$ per average watt. The cost of a kilowatt-hour of electricity from solar is about 20 to 30 cents; the cost of storing this energy roughly doubles that price. This compares with roughly 3 cents per kilowatt-hour in a coal-burning power plant. ${ }^{40}$ There is reason to expect that the cost of solar energy will fall. Mass production and the exploitation of learning curves in other manufacturing activities have led to even larger reductions in cost when the right economic drivers are in place. For example, the cost of a CD-ROM has come down by about a factor of 100 since the technology was first introduced; a similar reduction in the cost of photovoltaic systems could drive the price of solar energy below 1 cent per kilowatt-hour. The challenge is to develop the right incentives for such a transition to occur.

Because solar energy would probably be based on photovoltaic systems, it would lend itself naturally to hydrogen production for use as a fuel. If the price of electricity from solar conversion were to drop to 1 cent per kilowatt-hour, it would be cost-effective to use the electricity immediately to produce hydrogen. Even if only one-third of the electricity were actually recovered, it would still be competitive in today's market. Thus, although solar energy remains uneconomic today, one should not rule out the possibility of low-cost, large-scale solar energy entering the market some time during this century. This would make it possible to replace fossil or nuclear energy, and if a reduction in cost by a factor of thirty could be accomplished, solar energy would indeed represent a viable alterna-

38. The White Sands facility has 3,200 square miles of land. At a collection efficiency of $30 \mathrm{~W} / \mathrm{m}^{2}$, this area would collect $250 \mathrm{GW}$ of solar power, or about 2,200 TW-h a year, compared with 3,900 TW-h of electricity generated in the United States in 2003 (EIA data).

39. For data on the cost of solar energy, see, for example, the website www.solarbuzz.com, produced by a consulting firm that tracks solar energy prices.

40. See, for example, The Economist, "The Shape of Things to Come?" July 9, 2005, which quotes the price of electricity generated from coal at 2 cents a kilowatt-hour in the United States and roughly 4 cents a kilowatt-hour in Germany. 
tive. A program to develop low-cost solar energy should aim for a cost of 1 cent per kilowatt-hour, at which point the issues of intermittency (that is, that no electricity is generated at night or in cloudy weather) can be successfully overcome. If successful, solar energy alone could provide the energy required for a fully industrialized world society.

In summary, one can reasonably expect nonfossil energy options to provide some fraction of the world's future energy supply. Wind, hydroelectricity, ocean waves, and geothermal energy will likely be extremely competitive in certain regions, but the bulk of the energy will come from fossil, nuclear, or solar energy. Each of these last three options by itself could provide sufficient energy to satisfy world demand for at least the foreseeable future. Each also faces difficult problems, however. Fossil energy must overcome environmental constraints (mainly from carbon emissions), nuclear energy will have to overcome the challenges of antiproliferation and safety, and solar energy will have to overcome its current high cost.

\section{The Environmental Challenges of Fossil-Fuel Use}

According to the EIA, fossil fuels at present provide 85 percent of the commercial energy consumed worldwide. As noted above, fossil fuels are not in danger of running out, but for every ton of carbon consumed, 3.7 tons of $\mathrm{CO}_{2}$ is emitted into the atmosphere. ${ }^{41}$ Rapid growth in world energy demand, which needs to be satisfied if economic development is to proceed, makes it virtually impossible to phase out carbon-based fuels. Nevertheless, the total amount of $\mathrm{CO}_{2}$ that can safely be emitted into the atmosphere is limited-how limited is still subject to debate. We will argue here that, whatever approach is taken, it will be difficult to stop $\mathrm{CO}_{2}$ emissions in time, and that efforts to approach a net-zero-carbon economy need to start soon.

\section{The Risks of $\mathrm{CO}_{2}$ Emissions}

It is now understood that continued large-scale $\mathrm{CO}_{2}$ emissions resulting from fossil-fuel use will have complex, highly uncertain, and potentially

41. Based on the ratio of molecular weights of carbon (12) and $\mathrm{CO}_{2}(44)$. 
very serious effects on human society and global ecosystems. ${ }^{42}$ These effects are often summarized as "global warming," but that is too simple. Changing $\mathrm{CO}_{2}$ concentrations in the atmosphere will change not only temperatures but also many other aspects of the Earth's chemical, climatological, and biological processes. The scale of these effects is highly uncertain, but it is clear that they are operating globally. There are also large uncertainties regarding the scale of effects associated with any particular time path of atmospheric $\mathrm{CO}_{2}$ concentration, as well as regarding possible positive (and negative) feedbacks, which could produce much larger changes in $\mathrm{CO}_{2}$ concentrations as well as climate and ecosystem changes. The following are some of the major effects of increasing $\mathrm{CO}_{2}$ concentrations:

- Climate change. Rising $\mathrm{CO}_{2}$ concentrations, in conjunction with other greenhouse gases such as water vapor and methane, will raise land and ocean surface temperatures and will likely cause major changes in winds, rainfall, and ocean currents.

- Changes in ocean chemistry. Rising $\mathrm{CO}_{2}$ will acidify the surface waters of the ocean. Theoretical considerations and experimental and other empirical evidence all suggest that the resulting changes in ocean chemistry will stunt coral growth, possibly leading to the demise of these important ecosystems. ${ }^{43}$

- Habitat destruction. Changes in the climate and chemistry of various habitats are likely to provoke large-scale extinctions of vulnerable species with limited habitat ranges or limited mobility.

-Enhanced disease transmission. Many diseases are regulated by climate, including average temperature and precipitation. These climate effects are often complex and often interact. A decline in rainfall, for example, can intensify certain vector-borne diseases by pushing animal species into more limited watering and breeding areas. The geographic range of diseases such as malaria could expand significantly.

42. See Houghton and others (2001).

43. A general discussion of the consequences of carbonate chemistry changes driven by changes in atmospheric $\mathrm{CO}_{2}$ concentration is laid out in Kleypas, Buddemeier, and Gattuso (1999) and Kleypas and others (2001). It is worth stressing that the impact on coral reefs discussed here is due not to temperature changes but to changes in the ocean water carbonate chemistry, which in turn is driven by the increased partial pressure of $\mathrm{CO}_{2}$ over the water. 
—Changes in agricultural productivity. Higher temperatures, shifting growing seasons, changing species composition, and altered rainfall patterns could locally modify agricultural productivity. Rising atmospheric carbon concentrations could potentially boost yields through a direct "carbon fertilization" effect, although this is much debated. Some places may experience a rise in productivity (for example, higher-latitude environments through longer growing seasons and perhaps carbon fertilization), but others, particularly in the warm regions of the world, are likely to experience declines. Even if the net global impact were small, regional dislocations could be substantial.

-Increased natural hazards. It is generally thought that extreme weather events are likely to intensify as a result of warmer temperatures. The energy released in hurricanes seems to be increasing. Flooding and droughts are both likely to increase in some parts of the planet.

-Rising ocean levels. Ocean levels are likely to rise for two reasons: thermal expansion of seawater as it warms, and melting of land ice in Greenland and Antarctica. Rising ocean levels will submerge coastal areas, lead to higher sea surges during storms, and cause saline infiltration of coastal groundwater aquifers. Some small island nations may well be completely submerged.

-Positive feedbacks and abrupt change. There are several possible channels by which small increases in $\mathrm{CO}_{2}$ concentrations could lead to abrupt and large effects. These include rapid dislodging of the ice sheets of Antarctica and Greenland into the ocean, ${ }^{44}$ greatly accelerating the increase in sea level; melting of permafrost and gas hydrates, which could release methane from the tundra, leading to a massive expansion of greenhouse gas concentrations; abrupt shutdown of the thermohaline circulation of ocean currents, with consequent large-scale changes for equator-to-pole heat transfers; and abrupt reductions in surface albedo (whiteness), for example through melting of sea ice, leading to a sharp increase in absorption of solar radiation.

44. Our colleague Jim Hansen of NASA's Goddard Institute of Space Studies has pointed out that the simple-minded concept of glaciers melting from the top is likely to be wrong, and that in reality glaciers disintegrate far more rapidly from within and at the bottom of the glacier. Water that forms on the top is heavier than ice, and once there is enough for it to work itself to the bottom of the glacier, it would destabilize the glacier and accelerate its demise. Once the ice is in the ocean, by cooling the ocean it contributes to a positive feedback by reducing the radiative losses from the ocean to the sky. 


\section{Uncertainties and Implications}

There are enormous uncertainties regarding the links between $\mathrm{CO}_{2}$ concentrations and climate. As a basic point, $\mathrm{CO}_{2}$ by itself is unable to create enough of a greenhouse effect to significantly increase global temperatures, but simple back-of-the-envelope calculations as well as more sophisticated climatological models suggest that the warming due to $\mathrm{CO}_{2}$ increases the water vapor content of the atmosphere. Since water vapor is an even more powerful greenhouse gas, this causes additional warming. It is the effect of $\mathrm{CO}_{2}$ as a greenhouse gas plus the indirect effect of $\mathrm{CO}_{2}$ on water vapor that accounts for the overall effect.

To arrive at a first approximation of the amount of future warming, one might assume that the relative humidity of the atmosphere stays constant, in which case the predicted warming noticeably exceeds what has been experienced. The model simulations thus have to explain why the warming effect over the course of the twentieth century was smaller than anticipated, not larger. The standard explanation, and the one embraced by the Intergovernmental Panel on Climate Change (IPCC), invokes the additional effects of anthropogenic aerosols in the air. (Aerosols produced in combustion processes and other industrial activities tend to reflect sunlight and thus cool the Earth.) If that is indeed the case, the full force of the greenhouse warming exerted by past $\mathrm{CO}_{2}$ emissions has yet to occur.

Critics point out that the dynamics of the water cycle in the atmosphere are very complex and not well captured by the current generation of models. The anthropogenic greenhouse effect is quite small compared with the overall water-induced greenhouse effect and depends on fine details in the distribution of water between clouds and water vapor, and of the latter between the upper and the lower troposphere. Changes in these parameters could in principle also explain the lower-than-expected rise in temperature, in which case the eventual global warming may not be as large as has been suggested.

However plausible such alternative explanations may be ${ }^{45}$ they are ad hoc in that they provide no more than another possible way of reconciling the simple model calculations with actual observations. Furthermore, it is

45. Lindzen, Chou, and Hou (2001) provide an alternative explanation for the negative feedback on global average temperature, being careful to point out that their mechanism is a plausible one. 
worth noting that global average temperature is not a particularly good parameter for describing the impact of climate change. Climate change may manifest itself in some parts of the world in ways other than temperature change, for example as changes in the hydrologic cycle (evaporation and rainfall) ${ }^{46}$

Beyond the climate effects are the chemical changes on land and in the oceans due to $\mathrm{CO}_{2}$. Eutrophication (nutrient enrichment that favors plant growth, especially of certain plants) with $\mathrm{CO}_{2}$ in natural ecological systems can have complex impacts, and because these systems have found a subtle equilibrium at existing $\mathrm{CO}_{2}$ concentrations, changes in $\mathrm{CO}_{2}$ tend to disrupt them. As an example, consider the demonstrated fact that, because vines in the rainforest benefit more than trees from excess $\mathrm{CO}_{2}$, the weight of the more rapidly growing vines increases to the point that the trees supporting them are damaged. ${ }^{47}$ The impacts of excess $\mathrm{CO}_{2}$ on forests are complex and could entail feedbacks that are difficult to predict. For example, it appears that moderate-latitude forests in Europe and North America respond to excess $\mathrm{CO}_{2}$ by raising their overall carbon uptake, whereas high-latitude forests seem to turn into carbon emitters, as the carbon tied up in cold or frozen soil is more readily freed. ${ }^{48}$

Possibly the biggest impact of higher $\mathrm{CO}_{2}$ concentration that has been demonstrated outside of warming itself is the chemical change in the surface waters of the ocean. The surface ocean tends toward chemical equilibrium with the atmosphere. As the $\mathrm{CO}_{2}$ partial pressure in the air over the water increases, the dissolved $\mathrm{CO}_{2}$ in the ocean increases proportionally. It has been shown at Biosphere 2 that such changes lead to a reduction in carbonate fixation among calciferous organisms like corals: doubling the $\mathrm{CO}_{2}$ in the air would reduce the rate of coral growth by about 40 percent. ${ }^{49}$ Assuming that the reef is initially more or less in balance between growth and destruction, a reduction in growth by about 40 percent nearly ensures a serious decline of the reef.

Thus with very few model assumptions one can be nearly certain that the impact on coral reefs from a doubling of $\mathrm{CO}_{2}$ is large. Indeed, it is

46. A recent paper by Robert D. Cess (2005) reports evidence that would appear to contradict the claim of Lindzen, Chou, and Hou.

47. See Phillips and others (2002).

48. For a summary see Schlesinger and Andrews (2000).

49. The experiments at Biosphere 2 and their implications are discussed in Langdon and others (2000). 
very likely that coral reefs under these conditions will disintegrate. ${ }^{50}$ Since coral reefs are major centers of biodiversity in the tropical oceans, it again stands to reason that the impact of such a change on local ecosystems, and on the human communities that live on or near reefs, will be quite dramatic. Coral reefs thus provide an example of an ecological system that would be affected by increased greenhouse gas concentrations in several ways: by warming, by ocean level rise, and by ocean acidification.

\section{Dangerous Anthropogenic Interference}

The standard economic approach to the $\mathrm{CO}_{2}$ problem is to compare the costs of mitigation (abatement of carbon emissions) with the expected benefits (avoided environmental harms). Mitigation would then be pursued to the point where its marginal cost just equals the marginal benefit. A third dimension to consider is the potential for adjustment, whereby steps are taken to "live with $\mathrm{CO}_{2}$," for example by fortifying coastal zones, building artificial coral reefs, or planning for higher temperatures. Investments in adjustment are likewise made to the point where the marginal cost is equal to the marginal benefit.

The world community, however, has adopted a different approach, in theory if not in practice. The governing international law on climate is the 1992 United Nations Framework Convention on Climate Change. The UNFCCC commits all signatories-the United States and 188 other ratifying countries - to the "stabilization of greenhouse gas concentrations in the atmosphere at a level that would prevent dangerous anthropogenic interference with the climate system" (Article 2, emphasis added). Moreover, the article states that stabilization "should be achieved within a time-frame sufficient to allow ecosystems to adapt naturally to climate change, to ensure that food production is not threatened and to enable economic development to proceed in a sustainable manner" (Article 2). The climate treaty thus does not call for a balancing of the costs and benefits of avoiding climate change, but rather calls specifically for avoiding dangerous anthropogenic interference. It also notes that uncertainty is not a reason for inaction. The treaty does, however, note that measures

50. The possibility of a major collapse of coral reefs is discussed by Kleypas, Buddemeier, and Gattuso (2001). 
to avoid dangerous anthropogenic interference should be carried out in a cost-effective manner, minimizing the costs of achieving the goal:

The Parties should take precautionary measures to anticipate, prevent or minimize the causes of climate change and mitigate its adverse effects. Where there are threats of serious or irreversible damage, lack of full scientific certainty should not be used as a reason for postponing such measures, taking into account that policies and measures to deal with climate change should be cost-effective so as to ensure global benefits at lowest possible cost. (Article 3, paragraph 3)

The treaty also defines what it means by adverse effects on the climate:

"Adverse effects of climate change" means changes in the physical environment of biota resulting from climate change which have significant deleterious effects on the composition, resilience or productivity of natural and managed ecosystems or on the operation of socio-economic systems or on human health and welfare. (Article 1)

In short, the UNFCCC calls for a cost-minimizing approach to limiting significant deleterious effects on natural and managed ecosystems, rather than a balancing of overall costs and benefits of mitigation (and adaptation). This is a reasonable approach to a situation where significant ecosystem changes due to anthropogenic climate change are assumed to have large but also unquantifiable consequences on global society. In practice, however, the United States and some other countries (Australia, for example) have failed to respect this approach, reverting instead to a cost-benefit test. The Bush administration has argued that the costs of mitigation would exceed the benefits and has therefore rejected any specific climate targets.

Among European governments and analysts, the notion of setting limits on $\mathrm{CO}_{2}$ to avoid dangerous anthropogenic interference is much more popular. Two kinds of limits have been proposed. The first sets a standard for overall temperature increase (for example, a maximum of $2^{\circ} \mathrm{C}$ ) and then tries to back out the implied increase in $\mathrm{CO}_{2}$ and other greenhouse gases that would just fall short of raising temperature above the selected threshold. The second addresses the $\mathrm{CO}_{2}$ target directly, recognizing, among other things, that $\mathrm{CO}_{2}$ affects ecosystems through its chemical impacts as well as its climate impacts. A broad consensus under either approach is to aim for a maximum atmospheric $\mathrm{CO}_{2}$ concentration of somewhere between 450 and 560 parts per million (ppm), compared with the current $\mathrm{CO}_{2}$ concentration of $380 \mathrm{ppm}$ and the preindustrial baseline of $280 \mathrm{ppm}$. Many others have also called for a limit at or below 560 ppm (the so-called 
$2 \times$ standard, since $560 \mathrm{ppm}$ would represent a doubling of the preindustrial $\mathrm{CO}_{2}$ concentration). There is near unanimity in the climate science community that a tripling of the preindustrial concentration (to $840 \mathrm{ppm}$ ) would pose catastrophic risks given current scientific knowledge, including a high likelihood of melting of the Greenland and Antarctic ice sheets, with an attendant massive increase in sea levels, as well as a reasonable likelihood of triggering feedbacks that could lead to abrupt climate change.

Whatever the specific target, the fact is that unfettered economic growth over the next hundred years is likely to get to these high numbers and even beyond. Thus it becomes important to provide alternatives to the current energy infrastructure, and provide them soon. The simulation model presented later in this paper indicates that unconstrained consumption would lead to about 1,600 Gt of carbon emissions during the century, with a rise in the carbon concentration to around $900 \mathrm{ppm}$, far above almost all estimates of the threshold of dangerous anthropogenic interference.

\section{Toward a Robust Climate Policy}

The key choice on climate policy is whether, by how much, and by whom scarce economic resources should be expended on mitigating greenhouse gas emissions. Should energy be conserved? Should carbon emissions be captured and sequestered? By how much and at what cost? A robust mitigation strategy should accomplish four things:

-It should avoid breaching an irreversible danger zone, by aiming for a target low enough to avoid irreparable consequences of $\mathrm{CO}_{2}$ such as major species extinction or abrupt climate change. The target should be regularly reassessed in light of new scientific evidence.

- It should apply a global strategy of mitigation, since carbon concentrations depend on the volume of global emissions, not their distribution.

-It should minimize the present discounted value of costs by spreading out mitigation efforts over a long period.

- It should be equitable between rich and poor countries.

Given the uncertainties - and given the momentum of the increase in carbon concentrations in light of today's long-lasting energy infrastructure and rising global demand for energy services-it makes sense to aim for a target such as 450 to $500 \mathrm{ppm}$ by 2050 , and for a ceiling such as $560 \mathrm{ppm}$ (the $2 \times$ carbon standard) through the remainder of the century. The best current evidence is that levels between 450 and $560 \mathrm{ppm}$ 
threaten dangerous anthropogenic interference in ecosystem functions, although further study will shed more light on the specific dangers and thresholds.

U.S. opposition to these widely proposed limits would be understandable (and would likely prevail politically) if the economic cost of meeting such targets indeed proves astronomical. Fortunately, that does not seem to be the case. Although the technological options and their costs are uncertain, there are reasons to believe that the eventual economic costs will prove rather modest. We show in the next two sections that a target of 450 to $500 \mathrm{ppm}$ as of 2050 can most likely be achieved at a cost well below 1 percent of global gross product if the target is adopted early enough to stretch out the R\&D and research periods.

To minimize the total cost of mitigation, the adjustment path should involve low-cost investments in mitigation anywhere in the world, treating high-income and low-income countries alike. The present-value cost of mitigation averted should be equalized across regions and over time. In practice, a large part of the adjustment will take place in rapidly growing Asia. The world's rich countries should help to cover these costs on equity grounds. Investments in reducing carbon (for example, via power plants equipped with CCS) should be introduced gradually, as new facilities are installed, since mitigation in new installations is generally much less expensive than retrofitting. It is precisely because retrofitting is so expensive that mitigation will take decades, not years, and should be phased in with a very long lead time if target carbon concentrations are not to be breached.

The most promising low-cost options include the conversion of the global automobile fleet to low-emission vehicles, for example through the phased replacement of current vehicles by hybrids; and the introduction of CCS at all new fossil-fuel power plants and other large industrial facilities relying on fossil fuels.

\section{Scalable Carbon Management Options}

Although many technologies now compete for a share of the future energy market, only a very few can operate on the necessary scale, which will be measured in the tens of terawatts. There are three technology options that, each by itself, could in principle provide a solution to the cli- 
mate change problem and satisfy the world's energy demand. All three are unproven at the necessary scale, however, and all three require additional development. The first option, and the most compatible with current energy systems, is the introduction of CCS within the existing fossil-fuel regime to prevent the accumulation of $\mathrm{CO}_{2}$ in the atmosphere. The other two are nuclear and solar energy.

Complete transition to nuclear or solar energy would obviously eliminate the carbon problem. This section therefore focuses on the technologies required to transform the fossil energy sector into one based on a carbon-neutral infrastructure. Carbon-neutral fossil-fuel technology is important, since the world's energy infrastructure is today nearly exclusively based on fossil carbon. Eliminating what is currently by far the largest player from the mix would likely cause severe disruptions in energy supply. A better alternative is to develop means for CCS.

Most experts in the field consider carbon capture the more difficult part of the CCS problem. Here, however, we begin with a discussion of the carbon storage challenge, because storage is ultimately the binding constraint for fossil-fuel consumption. Disposing of a few million tons of $\mathrm{CO}_{2}$ would not be difficult with current technology. But to achieve a netzero-carbon world economy while still operating with fossil fuels, one needs technologies for the disposal of thousands of gigatons of $\mathrm{CO}_{2}$ over the course of the century. The challenge for storage thus lies in the size and the permanence of the available storage options. ${ }^{51}$

One has to capture the $\mathrm{CO}_{2}$ before it can be stored, of course, and this is most easily accomplished at large, concentrated sources of $\mathrm{CO}_{2}$, the largest of which are power plants. Thus one needs technologies for costeffectively capturing $\mathrm{CO}_{2}$ at power plants, but also at hydrogen production plants and other large, concentrated sources such as steel furnaces and cement kilns. ${ }^{52}$

A third enabling technology would make it possible to capture $\mathrm{CO}_{2}$ directly from the air. This can be done today by growing biomass, but it is also worth considering chemical systems that can do the same. An efficient means of collecting $\mathrm{CO}_{2}$ from the atmosphere would change the picture dramatically, as it would enable the continued use of carbon-based

51. Lackner (2003).

52. Metz and others (2005). 
fuels in small, dispersed, and mobile applications such as automobiles and airplanes without concern for the $\mathrm{CO}_{2}$ consequences. ${ }^{53}$

\section{Carbon Storage Options}

Carbon storage in biomass has been suggested as one option for sequestering carbon. Although such storage is certainly feasible, it is fundamentally limited in scope. The world's existing biomass contains $600 \mathrm{GtC}$ (equivalent to 2,200 $\mathrm{Gt}$ of $\mathrm{CO}_{2}$ ), and any attempt to raise this number substantially would be limited by the environmental consequences ${ }^{54}$ Even to increase world biomass by $100 \mathrm{GtC}$ would be a very large change, and maintaining the stock of biomass at that level would require a continuous effort. Without active intervention, the biomass produced will revert to $\mathrm{CO}_{2}$ over the course of a few years or at most (in the case of hardwood) a few decades. Thus biomass storage is not permanent enough to be considered a solution to the $\mathrm{CO}_{2}$ capture problem.

In any case, growing biomass for the sake of capturing $\mathrm{CO}_{2}$ and then storing the valuable biomass appears counterproductive, except in areas of high biodiversity where biological conservation rather than carbon management is the core goal. In other areas it would make more sense to convert this biomass into a fuel. However, this could result in valuable agricultural land being used to produce fuel that is lower in value than the food crop it would replace.

Other options for carbon storage include disposal in the ocean, underground injection of $\mathrm{CO}_{2}$ into geological formations, and chemical fixation of $\mathrm{CO}_{2}$ as a solid carbonate..$^{55}$ Disposal in the ocean in effect short-circuits the natural carbon cycle: about 70 to 80 percent of emitted $\mathrm{CO}_{2}$ will eventually find its way into the ocean. ${ }^{56}$ Thus injecting $\mathrm{CO}_{2}$ into the ocean rather than releasing it into the atmosphere reduces the temporary excess in the air that produces the greenhouse effect. Ocean disposal takes advantage of a larger reservoir that can handle a larger $\mathrm{CO}_{2}$ load, thereby reduc-

53. Lackner, Ziock, and Grimes (1999).

54. See, for example, the summary of the carbon cycle science in Schimel and others (1995).

55. A recent IPCC report on carbon capture and storage discusses in detail the state of the art in this field (Metz and others, 2005).

56. See, for example, Kheshgi and Archer (2004). 
ing the size of the problem. The world's oceans could store an additional $1,200 \mathrm{GtC}$ before reaching equilibrium with an atmosphere that has twice the preindustrial $\mathrm{CO}_{2}$ content. ${ }^{57}$ This is far less than the $39,000 \mathrm{GtC}$ already dissolved in the ocean, ${ }^{58}$ but it would represent a fairly large fraction of total emissions. However, in such a scenario one is committed to a doubled $\mathrm{CO}_{2}$ in the atmosphere for many thousands of years.

There is no practical way of achieving a completely uniform dissolution of injected $\mathrm{CO}_{2}$ throughout the world's oceans. Thus one must also consider the environmental consequences of acidification by $\mathrm{CO}_{2}$ where it actually occurs. Changing the $\mathrm{CO}_{2}$ content of the upper ocean so that it is in equilibrium with a doubled partial pressure of $\mathrm{CO}_{2}$ in the atmosphere would significantly change the carbonate chemistry of the surface waters. It has been demonstrated that such a change would stunt coral growth. The effects on deepwater ecological systems are less well understood.

As long as the atmosphere remains in chemical equilibrium with the ocean, the injected $\mathrm{CO}_{2}$ will stay in the ocean indefinitely. However, if the ocean comes to contain more $\mathrm{CO}_{2}$ than what is in balance with the atmosphere, the $\mathrm{CO}_{2}$, even if injected at great depths, will return to the atmosphere in less than the ocean turnover time, which is less than 1,000 years. ${ }^{59}$ For carbon stored at medium depths, the storage time is only a few hundred years. The conclusion is that the environmental impact of ocean storage combined with short storage times makes ocean storage an option of last resort, and not a very attractive one at that.

A more permanent method of $\mathrm{CO}_{2}$ storage would be injection into underground reservoirs. This is already done on a relatively small scale for enhanced oil recovery. $\mathrm{CO}_{2}$ from gas wells in Colorado is shipped via pipeline to West Texas, where it is injected into oil fields to help increase production. ${ }^{60}$ Oil companies have paid as much as $\$ 15$ a ton for this $\mathrm{CO}_{2}$ in the past; current market conditions would allow for higher prices. Part of the injected $\mathrm{CO}_{2}$ stays underground, and any that comes back to the surface is recovered and reused. Thus virtually none of the $\mathrm{CO}_{2}$ delivered to the well escapes.

57. This number was first explained by Takahashi and is discussed in some detail in Lackner (2002).

58. Details of the size of the sinks are provided in Schimel and others (1995).

59. See, for example, Archer, Kheshgi, and Reimer (1997).

60. Details can be found in Metz and others (2005). 
Whereas in Colorado and West Texas the $\mathrm{CO}_{2}$ itself is fossil gas extracted from underground, in future enhanced oil recovery operations the $\mathrm{CO}_{2}$ could be the waste stream of fossil-fuel consumption. Use of waste stream $\mathrm{CO}_{2}$ in enhanced oil recovery would thus remove excess carbon from the environment, even though it helps bring additional carbon to the surface. The advantage of this storage option is that it actually results in an economic benefit that can at least partly offset the cost of $\mathrm{CO}_{2}$ capture. Estimates of the storage capacity associated with enhanced oil recovery vary but are on the order of 60 to $200 \mathrm{Gt}$ of $\mathrm{CO}_{2}$, well short of what will ultimately be needed. Nevertheless, this process provides a starting point for geological sequestration that would allow the phasing in of the new technology. ${ }^{61}$

Other fossil-fuel reservoirs could also be considered. Economic benefit might be derived from maintaining pressure in natural gas reservoirs or injecting $\mathrm{CO}_{2}$ into coal beds too deep to be mined, in order to displace the methane bound to the coal. ${ }^{62}$ Over the last twenty years such coal beds have become a sizeable resource for methane production in the Rocky Mountain region. $\mathrm{CO}_{2}$-aided recovery of deep coal bed methane is still in its infancy, however, and has to overcome a number of hurdles before it could become commonplace.

Once all the underground reservoirs at which injecting $\mathrm{CO}_{2}$ provides an economic benefit have been filled, $\mathrm{CO}_{2}$ could still be injected into other sites that provide a storage opportunity only. Numerous abandoned oil and gas fields exist around the world, some of which could absorb large amounts of $\mathrm{CO}_{2}$. A difficulty with this approach is that a large number of existing boreholes would have to be secured and sealed to prevent $\mathrm{CO}_{2}$ from leaking back to the surface.

The largest available $\mathrm{CO}_{2}$ sinks are deep saline aquifers that have not been drilled and therefore pose little concern about leakage. The Norwegian company Statoil is already using such a reservoir at a drill platform in the North Sea to dispose of the $\mathrm{CO}_{2}$ removed from natural gas produced at the site. (The natural gas from these wells contains approximately 10 percent $\mathrm{CO}_{2}$, which has to be stripped out in order for the gas to meet industrial standards.) In the past such $\mathrm{CO}_{2}$ would have simply been released into

61. Metz and others (2005).

62. Coal bed methane is discussed in Metz and others (2005). 
the atmosphere, but Norway now charges about $\$ 50$ per ton of $\mathrm{CO}_{2}$ for such emissions. ${ }^{63}$ In response, Statoil has chosen to strip the $\mathrm{CO}_{2}$ from the gas not at a remote station on land but directly on the platform, reinjecting the $\mathrm{CO}_{2}$ into a saline aquifer 800 meters below the seafloor. ${ }^{64}$

This platform, which has been operating since 1996, injects about 1 million tons of $\mathrm{CO}_{2}$ a year. The gas appears to have remained in place, gradually distributing itself along the top seal of the aquifer. A number of similar sites will come online over the next few years. Technical issues with regard to safety and long-term stability are still debated in the scientific community. Nevertheless, it seems clear that these formations have a substantial capacity that is safe and that can contain the injected $\mathrm{CO}_{2}$ for all practical purposes indefinitely.

The cost of injection underground is small: typical estimates given in the IPCC report range from around $\$ 0.50$ to $\$ 8$ per ton of $\mathrm{CO}_{2}$, which, at the Norwegian field described above, would add 2.5 to 40 cents to the cost of a gigajoule of natural gas ${ }^{65}$ The cost of stripping the $\mathrm{CO}_{2}$ out of the natural gas stream is higher but had to be paid in any case.

Underground injection thus provides an option for carbon storage at a sufficient capacity to last for decades. As the amounts stored increase, however, concerns over leakage will grow. For example, if 1,000 Gt of stored $\mathrm{CO}_{2}$ leaks one part per thousand per year, the resulting annual emission of $1 \mathrm{Gt}$ is significant. The challenges of safety, permanence, and cost will determine the effective size of the available storage capacity. The more severe the constraints, the smaller the number of reservoirs that will meet the necessary criteria. As a result, it is difficult to predict how much capacity will actually be available. However, simple dimensional analysis suggests that the available capacity will have difficulty accommodating all the $\mathrm{CO}_{2}$ that is likely to be produced. Consider that, in liquid form, all the $\mathrm{CO}_{2}$ expected to be produced in the United States over the next fifty years would cover the entire U.S. land area to a depth of about $5 \mathrm{~cm}$. Storing such a huge volume will indeed present a challenge.

The last option for $\mathrm{CO}_{2}$ disposal is chemical conversion into solid carbonates. Although this process is inherently more expensive, because it

63. The actual price is set in Norwegian currency and thus fluctuates slightly in dollar terms. For a summary see Herzog, Eliasson, and Kaarstad (2000).

64. Metz and others (2005).

65. Metz and others (2005, p. 33). Monitoring costs add 10 to 30 cents per ton of $\mathrm{CO}_{2}$ to the cost of injection. 
requires a chemical base against which the carbonic acid formed from $\mathrm{CO}_{2}$ and water is neutralized, it solves the problems of permanence, safety, and capacity. Once formed, the carbonates are stable and will not release the $\mathrm{CO}_{2}$ back into the atmosphere. They are also environmentally benign and indeed occur in large quantities naturally. The resource base for forming carbonates far exceeds the availability of fossil fuels and thus cannot be exhausted.

The carbonation reaction is akin to chemical weathering, where magnesium and calcium silicates are transformed into stable, solid carbonate. Carbonation does not require high temperatures; indeed, it happens spontaneously at normal ambient temperatures, but the reaction rates are very small, and the technology for speeding up these reactions is still under development. ${ }^{66}$ The mining operations needed to provide the raw mineral base would be very large, but no larger than the associated operations for mining coal. The challenge is the cost of the chemical conversion itself. Current technology would set the price at about $\$ 80$ per ton of $\mathrm{CO}_{2}$, but improvements in the chemistry could drive the price down. For mineral sequestration to become practical, the cost of disposal should not exceed about $\$ 30$ a ton, at which point it becomes comparable to the cost of the other steps in the process. It would not be possible to lower the price much further, because mining and tailing disposal, mature technologies with little room for improvement, would add about $\$ 10$ per ton of $\mathrm{CO}_{2}{ }^{67}$

In summary, carbon storage could start today with underground injection, the cost of which would in many cases be more than offset by the benefit obtained by extracting additional oil or gas. After these by-product reservoirs are used up, a large storage volume is available for which the cost of storing and monitoring the $\mathrm{CO}_{2}$ is very small. Whether or not these reservoirs have sufficient capacity to meet the needs of the coming century is not yet clear, but behind this option is yet another option, mineral sequestration. The cost of the chemical processing under this option, however, would have to fall by about a factor of four to five to keep the cost of energy within 30 percent of what it is today. But this degree of improvement is actually small compared with what would be needed for the introduction of fuel cells or solar cells, whose costs are one or two orders of

66. Lackner (2002).

67. Mineral sequestration is discussed in detail, including price ranges, in the IPCC report on carbon capture and storage (Metz and others, 2005). 
magnitude above competitive levels. CCS is, in fact, such an attractive option that testing its feasibility in many different parts of the world should be among the highest policy priorities. If long-lasting and inexpensive storage options can be found, as now seems a reasonable presumption, CCS will very likely provide an important mitigation strategy for decades to come.

\section{Carbon Capture at Large Sources}

Before $\mathrm{CO}_{2}$ can be disposed of, it needs to be captured and transported to the disposal site. Transport does not pose any new challenges, but capture will require new technologies. The obvious place to capture $\mathrm{CO}_{2}$ is at those places where it is produced in large, concentrated amounts. The largest of these sources are power plants that operate on fossil fuels.

Conceptually, the easiest way of capturing the $\mathrm{CO}_{2}$ produced by fossilfuel combustion is to scrub it from the flue (exhaust) gas. This option has been well explored and typically entails roughly a 30 percent energy penalty; ${ }^{68}$ that is, the scrubbing operation itself consumes roughly onethird of the plant's energy output. The addition to the price of electricity would be similar. The biggest downside of this technology is that, when installed as a retrofit, it leaves the plant running at far from optimal efficiency. Since the cost of $\mathrm{CO}_{2}$ scrubbing far exceeds the cost of the coal input, a power plant that collects its own $\mathrm{CO}_{2}$ would need to be substantially reoptimized for greatly improved efficiency. As a result, retrofitting capture technology is far more costly per unit of energy produced than installing such technology in a new plant.

Alternatively, a power plant can operate on pure oxygen rather than air. In this case the flue gas is a mixture of $\mathrm{CO}_{2}$ and water, which can easily be separated. Flue gas recycling would keep the temperature of the boiler at tolerable levels. Such plants may achieve slightly higher efficiencies, but they, too, would commit about 24 to 40 percent of their electric output to separation, in this case of oxygen from the air. ${ }^{69}$ The costs are similar to those in the case described above.

68. Metz and others (2005, p. 25). The figure reported for a new pulverized coal plant is a 24 to 40 percent increase in the energy requirement due to capture, with a representative value of 31 percent.

69. The Swedish electricity company Vattenfall is building such a plant south of Berlin (company press release dated May 19, 2005). For a description of the technology see Andersson, Johnsson, and Strömberg (2003). 
The energy penalty is much smaller in integrated gasifier combined cycle (IGCC) plants and in some cases could be eliminated. In these plants coal is converted into a combustible gas, which is then combusted to drive a turbine, with the waste heat used to create steam. It is possible to convert the gas upstream of the turbine into a stream of hydrogen and collect the $\mathrm{CO}_{2}$ upstream of the turbine, where it is already pressurized.

The ultimate design of a power plant operating on fossil carbon would combine high efficiency, $\mathrm{CO}_{2}$ capture, and clean operation. Such a plant would use fuel cells to oxidize the fuel gas into $\mathrm{CO}_{2}$ and water. ${ }^{70}$ It could gasify coal and capture the $\mathrm{CO}_{2}$ upstream of the fuel cell while producing hydrogen, or remove the $\mathrm{CO}_{2}$ downstream after the carbonaceous gas has been oxidized in a solid oxide fuel cell. Either way, or in a hybrid design that does a little of both, it is possible to achieve extremely high energy conversion efficiencies while completely eliminating emissions of all pollutants into the atmosphere. Since the nitrogen from the air is not mixed with the combustion products and the $\mathrm{CO}_{2}$ is disposed of permanently, there is no gaseous effluent left. It is therefore possible to cap the flue stack and take advantage of the synergies between eliminating pollution and avoiding $\mathrm{CO}_{2}$ emissions.

At an energy and cost penalty on the order of 30 percent, it is thus possible to build new power plants that capture all the $\mathrm{CO}_{2}$ they produce but are otherwise very similar to current designs. The cost of retrofitting will always be substantially higher than in new plants, because the old plants were simply not designed for these changes. Over time the efficiency of new plants with carbon capture will increase, and future plants that operate with coal as a fuel will almost certainly involve coal gasification and a gradual decarbonization of the fuel gas before its combustion in a gas turbine. Such plants, in effect, produce hydrogen before they produce electricity. By producing a hydrogen output rather than an electricity output, they also open the door to decarbonizing other sectors of the energy economy.

\section{Coping with Decentralized Emissions of $\mathrm{CO}_{2}$}

For dispersed and often mobile sources of $\mathrm{CO}_{2}$, capture at the source is usually not an option. This is best seen in the example of automobiles. The combustion of $1 \mathrm{~kg}$ of gasoline produces about $3.1 \mathrm{~kg}$ of $\mathrm{CO}_{2}$. Since $\mathrm{CO}_{2}$ is

70. Yegulalp, Lackner, and Ziock (2001). 
a gas at standard temperatures and pressures, collecting it requires either a pressure tank or an absorbent material to which it can attach. Either adds weight to the vehicle, making this solution very impractical.

The remaining options are threefold. First, one can reduce the need for carbonaceous fuels in the distributed energy sector by dramatically raising efficiency. Second, one can replace these fuels with carbon-free energy carriers such as electricity and hydrogen. Finally, one can compensate for the $\mathrm{CO}_{2}$ emitted by these sources by removing an equivalent amount of $\mathrm{CO}_{2}$ from the air.

The largest contributor to distributed emissions is the transportation sector. However, the distributed use of small boilers, furnaces, and other energy applications in industry, as well as for residential energy consumption, also contributes to the roughly 50 percent of the energy sector that is not amenable to capture of $\mathrm{CO}_{2}$ at the source.

LOW-EMISSION VEHICLES. In the transportation sector a transition to higher fuel efficiency is already under way. Today's hybrid gasolineelectric automobiles in Japan and the United States and diesel automobiles in Europe are much more energy efficient than previous generations. Hybrids ultimately offer great potential for improvement, as electric engines are far more efficient under variable load. They can also deliver high torque at low speed, which is difficult for an internal combustion engine to do. The new generation of hybrids has demonstrated that the energy inefficiencies that arise from a dual power source are more than overcome by the improved efficiency of the engine itself. Over time, as batteries become more advanced, hybrid efficiency is likely to rise, and topping off hybrid automobiles with electricity from dispersed outlets will greatly diminish the need for gasoline. Many trips today involve short distances, making it technically feasible to charge the battery before the trip and recharge it at the destination. Thus the carbon reductions made possible by such a vehicle could be even more dramatic than simple mileage improvements would suggest. It appears that gasoline prices are already sufficiently high to drive this transition to hybrids and diesels, raising the question of whether one should not properly consider it as part of the continuous endogenous improvement in the carbon intensity of the economy. In any event hybrids and diesels have the potential to greatly reduce $\mathrm{CO}_{2}$ emissions in the transportation sector, at virtually no additional cost to the consumer. 
ELECTRIFICATION OF THE COMMERCIAL AND RESIDENTIAL SECTOR. The most commonly used carbon-free energy carrier is electricity. Electricity's use is limited to higher-value applications, because electricity is in general more expensive than the chemical fuels often used in the residential and commercial sectors to generate heat. (Current market conditions in the United States, where natural gas has become as expensive as electricity, are either an aberration or a reflection of the scarcity of natural gas.) Replacing natural gas and liquid fuels with electricity would eliminate distributed sources of $\mathrm{CO}_{2}$. However, converting electricity directly into heat is an inefficient use of this high-quality energy resource. A more appropriate use of electricity in heating is to operate a heat pump, which uses electricity to transfer heat from a low-temperature to a hightemperature reservoir. Used in this manner, electricity can provide more energy in the form of heat to a building than is consumed in its generation. Whether such strategies become generally accepted will in part depend on advances in heat pumps and on their cost-effectiveness. With heating needs satisfied either by renewable energy or by electricity that has been generated in a carbon-neutral manner, it is possible to eliminate essentially all carbon emissions from the commercial and residential sectors. A similar strategy will help in many of the industrial sectors.

HYDROGEN. What is left is the use of boilers and furnaces, which are often difficult to replace with electric heating. Here it is possible to consider piping hydrogen in from a large plant that produces low-cost hydrogen from coal or other low-cost hydrocarbons. This concentrates the $\mathrm{CO}_{2}$ emissions into fewer places and thus makes carbon capture possible.

Hydrogen in principle could also move into the transportation sector, but its storage on board automobiles poses a serious challenge. Even using high pressures, the technology of hydrogen-based vehicles has to make extraordinary efforts to achieve the high fuel efficiencies that allow for acceptable travel distances between refueling stops. Such efficiency improvements would also help hydrocarbon-fueled vehicles and thus keep the playing field permanently tilted in their favor. Hydrogen as an energy carrier is more suitable to stationary applications; it then becomes an economic issue whether electricity or hydrogen provides the cheaper alternative.

EXTRACTION OF $\mathrm{CO}_{2}$ FROM THE AIR. A final alternative is capture of $\mathrm{CO}_{2}$ from the air. It has been shown that the concentration of $\mathrm{CO}_{2}$ in the atmosphere is sufficiently high to allow for its efficient extraction. Indeed, 
a $\mathrm{CO}_{2}$ collection device could be made nearly a hundred times smaller than a windmill yet eliminate the same amount of $\mathrm{CO}_{2}$ as would be emitted by the fossil-fuel combustion that the windmill would replace. As an illustration, to provide $10 \mathrm{~kW}$ of primary wind energy (roughly the amount of energy consumed per capita from fossil fuels in the United States) requires a windmill with a sweep area of roughly $80 \mathrm{~m}^{2}$. Yet the $\mathrm{CO}_{2}$ emitted in producing $10 \mathrm{~kW}$ of energy from fossil fuel could be captured by a collector with a sweep area of less than $1 \mathrm{~m}^{2} .{ }^{71}$

The cost of $\mathrm{CO}_{2}$ capture from the air is dominated not by the machines that collect the $\mathrm{CO}_{2}$, but by the process of recycling the sorbent to which the $\mathrm{CO}_{2}$ is bound. Thermodynamics shows that the recovery process need be only slightly more expensive than the equivalent process at a power plant. As a consequence, it appears feasible, but has not yet been proven, that $\mathrm{CO}_{2}$ capture from the air could compensate for the $\mathrm{CO}_{2}$ emissions from distributed sources such as cars and airplanes. Current cost estimates for this capture approach show that it could be done with currently available, unmodified processes for less than $\$ 100$ per ton of $\mathrm{CO}_{2} \cdot{ }^{72} \mathrm{An}$ appropriate goal for the cost of such a process would be around $\$ 30$ a ton, which would add about 25 cents to the price of a gallon of gasoline. ${ }^{73}$

\section{Robust Energy Policies}

Here we present a simple numerical scenario that demonstrates five robust conclusions. First, assuming that global economic growth continues, the world will increasingly rely on lower-grade carbon sources such as coal, and presumably on coal-to-liquid (Fischer-Tropsch and possibly other) conversion technologies. Second, it will be impossible to prevent carbon emissions from doubling during this century on a business-asusual course: the rate of global economic growth will easily overwhelm business-as-usual reductions in energy intensity. Third, the economic costs of keeping atmospheric concentrations of $\mathrm{CO}_{2}$ below $500 \mathrm{ppm}$ between now and 2050 will not be large relative to the size of the world economy,

71. For a more detailed discussion see Lackner, Ziock, and Grimes (1999).

72. Zeman and Lackner (2004).

73. This goal is based on the observation that the collection apparatus is small and will likely add little cost, and that the cost of the required inputs (oxygen and coal) is substantially below $\$ 30$ a ton. 
assuming that the costs are spread over time and that promising technologies (CCS and hybrid) prove effective on a large scale. Fourth, yetunproven technologies will probably be needed in the second half of this century, such as large-scale solar and possibly nuclear energy, combined with carbon-free energy carriers (such as hydrogen) for industry, transport, and residential and commercial use. Fifth, given the likelihood of hitting the carbon doubling limit on a business-as-usual course, there is an overwhelming case for early action on all low-cost fronts.

The four key assumptions of the scenario design are the following:

- The world economy can be represented by eight economic regions, all of whose incomes per capita gradually converge to that of the United States.

-Trend real economic growth in the United States continues at 1.7 percent a year.

-World population grows according to the UN Population Division's medium forecast.

-Underlying energy efficiency gains of 1.5 percent a year are achieved in all sectors.

The immediate policy prescriptions are the following:

-Crude oil will need to be gradually replaced with coal, converted to liquid fuel using the Fischer-Tropsch process.

- Carbon mitigation policies, especially promotion of CCS and hybrid vehicles, will need to be introduced in timely fashion.

The key implications of our analysis are the following:

- Carbon concentrations must be kept below 500 ppm as of 2050.

- The cost of mitigation will be much less than 1 percent of gross world product as of 2050 .

—Additional mitigation policies will be needed after 2050 .

\section{Scenarios}

We divide the world into eight regions: the United States, Western Europe, other developed economies (ODE), the transition economies, China, India, other emerging Asian economies (OEAE), and all other emerging economies (OEE). For convenience, we broadly follow the geographical divisions used by the EIA. For all regions gross product is measured in purchasing-power-parity terms, in current 2002 international dollars. Each region comprises four energy-using final sectors: residential, commercial, transport, and industry. Each of these sectors uses pri- 
mary energy directly and uses electricity, which in turn uses primary energy. These sectoral divisions also follow those of the EIA. Primary energy is divided into five types: oil, gas, coal, nuclear, and renewable.

The United States is presumed to grow at an underlying real growth rate of 1.7 percent a year, the long-term trend observed for the U.S. economy since early in the nineteenth century. This growth rate is slightly below that observed between 1950 and 1998 as measured by Angus Maddison. ${ }^{74}$ The United States functions as the technological leader of the world, and incomes in all other countries are assumed to converge toward U.S. income per capita in a standard convergence pattern.

Specifically, we let $Y(t)$ be U.S. real income per capita, given by $Y(t)=$ $Y(0)(1.017)^{t}$. For income in any other region $Y^{*}$, we define the initial income gap with the United States in logarithmic terms as $g^{*}(0)=$ $\ln \left[Y(0) / Y^{*}(0)\right]$ and then assume gradual convergence as follows: $g^{*}(t)=$ $0.98^{t} g^{*}(0){ }^{75}$ For any period $t, Y^{*}(t)=Y(t) \exp \left[-g^{*}(t)\right]$. Under this specification, as $t \rightarrow \infty, g^{*}(t) \rightarrow 0$, and $Y^{*}(t) \rightarrow Y(t)$. We can refine this slightly by assuming that $Y^{*}$ converges not to $Y$, but to some fraction $\beta$ of $Y$. In that case the $\log$ gap is defined as $g^{*}(t)=\ln \left[\beta Y(t) / Y^{*}(t)\right]$. The assumption that $\beta<1$ accommodates any persisting problems of governance, geography, or institutional factors that would lead to a long-term proportionate gap between $Y$ and $Y^{*}$.

We choose values of $\beta_{i}<1$ for each non-U.S. region $i .^{76}$ This assumption leads to incomplete convergence in incomes per capita and to slower global output growth than if $\beta_{i}=1$. Two of our key findings-that global oil supplies will be strained by global growth and that the business-asusual emissions path will exceed prudent limits on atmospheric carbonwould be even stronger if we instead assumed $\beta_{i}=1$ for all regions. Thus, although we prefer to err on the side of caution in projecting global growth, we can still make strong and robust claims about the need for alternative fuels and control of carbon emissions.

In projecting world population, rather than use the United Nations' fiveyear interval estimates, we smooth the UN medium forecast by taking the UN figures for 2002 (the base year), 2025, 2050, and 2100 and then fitting

74. Maddison (2001).

75. This assumption of a 2 percent annual reduction of the log gap is in line with the estimates of Barro and Sala-i-Martin (1995, p. 38).

76. The baseline values for $\beta_{i}$ are Western Europe, 0.8; ODE, 0.9; transition economies, 0.75; China, 0.8; India, 0.8; OEAE, 0.75; and OEE, 0.5. 
a smooth geometric growth rate between these points. This smoothing is done for simplicity but has little effect on the results.

Finally, we model a baseline case for demand for primary energy and electricity as follows. Let $S_{i j}$ be the demand for primary energy in region $i$, sector $j$. We assume that primary energy demand grows in proportion to output growth in each region minus an energy efficiency saving of 1.5 percent a year. Thus $S_{i j}(t)=S_{i j}(0)\left[\mathrm{GNP}_{i}(t) / \mathrm{GNP}_{i}(0)\right](0.985)^{t}$. The demand for each kind of primary energy (oil, gas, coal, nuclear, renewable, and electricity) is treated as a fixed proportion of $S_{i j}$ based on actual proportions in 2002, which is the baseline year for the EIA's modeling. Thus demand in each sector for each type of primary energy and electricity is assumed in the baseline to grow in proportion to the sector's overall demand for energy. ${ }^{77}$

These "business-as-usual" projections are optimistic in that they assume smooth, continuous growth in the world economy for decades to come, with no global or regional convulsions or crises. We are asking whether convergent global growth-in which the U.S. economy continues to grow at historic rates, while other economies gradually converge toward it-is consistent with energy supply and climate constraints given unchanged fuel use composition and unchanged emissions per unit of energy consumed. The answer is no. Other fuels will need to substitute for oil (and probably natural gas), and carbon emissions per unit of energy use (and per unit of GNP) will have to decline sharply.

In the baseline scenario, shown in figure 3, gross world product grows from $\$ 46.3$ trillion in 2002 to $\$ 277.5$ trillion in 2050 (again, in constant 2002 dollars at purchasing power parity) and $\$ 910$ trillion by 2100 . This is the result of income per capita rising from a world average of around $\$ 7,500$ in 2002 to $\$ 31,000$ in 2050 , and world population rising from 6.2 billion in 2002 to 8.9 billion in 2050. Figure 3 also shows the projections for developed and developing regions (with the transition economies included along with the United States and Western Europe in the former). Output in today's developing regions, which account for roughly five-sixths of the world's population, comes to outstrip that of the developed regions as convergent economic growth occurs. Whereas in 2002 the developed regions accounted for 60 percent of global gross

77. Data on energy use by region and sector are taken from EIA (2005b) and from supporting documents of the EIA. 
Figure 3. Gross World Product in Baseline Scenario, 2002-2100

Trillions of 2002 dollars $^{\mathrm{a}}$

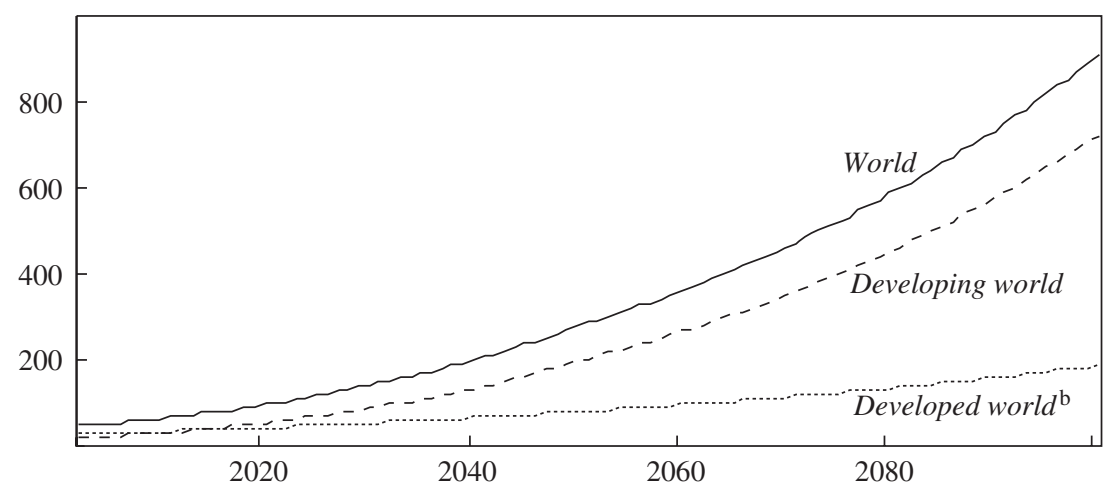

Sources: United Nations Population Division data; authors' projections.

a. Adjusted for purchasing power parity.

b. Includes transition economies.

product, by 2025 that share declines to 41 percent, and by 2050 to a mere 29 percent. As of 2100 in the baseline, the share of today's developed countries in global gross product is reduced to 21 percent.

With energy use in each region assumed to grow at the region's output growth rate minus the annual 1.5 percent efficiency gain, at the end of a half century this efficiency gain cumulates to roughly a 50 percent reduction in energy use per dollar of output. Thus, with gross world product growing a bit less than sixfold by 2050, world demand for primary energy grows approximately 2.8 -fold by 2050 and 4.3 -fold by 2100 , as shown in figure 4.

Of course, this smooth growth trajectory may well not materialize. It surely presumes global peace, relatively good long-term governance in the developing countries, broad global stability, and the supply-side availability of the needed energy resources and other natural resources (such as water, arable land, and minerals) at a low enough economic cost not to choke off growth. It assumes that climate change itself does not upset the growth path through the onset of massive food crop failures or other natural disasters. It assumes that no major pandemic disease upsets the overall path of demographic and economic change. 
Figure 4. World Energy Demand in Baseline Scenario

Quadrillion BTUs

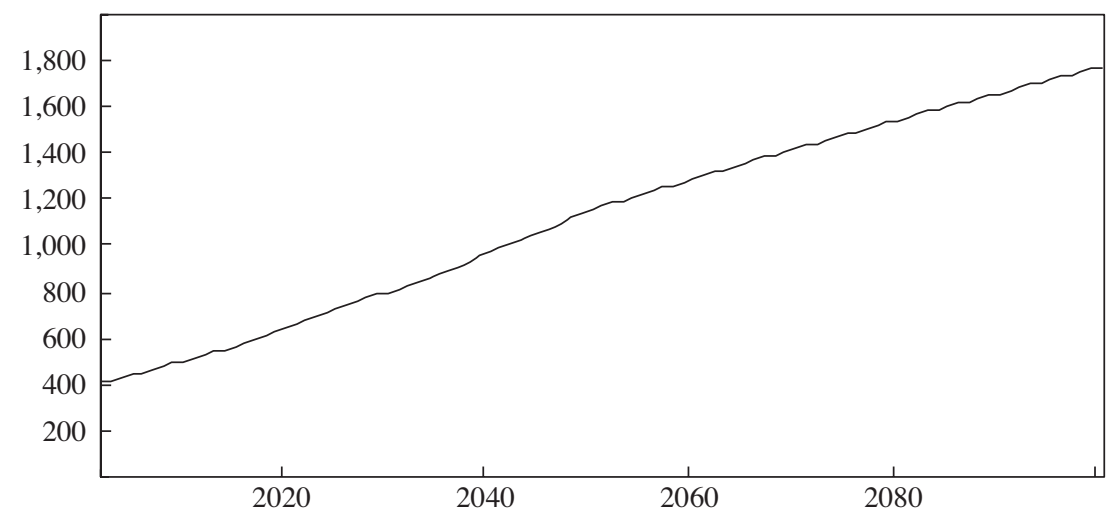

Source: Authors' projections.

\section{Growth of Atmospheric Carbon in the Baseline}

To understand the implications for the global climate of the rise in energy use, we need to translate the implied energy use into total annual emissions of $\mathrm{CO}_{2}$ and then translate those emissions into a rising path of atmospheric carbon concentration. This last step requires an additional set of calculations. According to the basic geochemistry of the carbon cycle, part of each year's carbon emissions will remain in the atmosphere, part will be dissolved in the ocean, and a third part will be incorporated into terrestrial biota and soils. A formal large-scale ocean-atmosphere-terrestrial model is needed to account for the complexity of the carbon cycle, and even with such models important uncertainties remain. For our use here, however, a back-of-the-envelope calculation using the underlying physical logic of atmosphere-ocean diffusion exchange can give a rough idea of the implications of a threefold increase in carbon emissions. The formal calculations are described in an appendix available from the authors.

Figure 5 shows our modeling assumptions about atmospheric carbon concentrations that would be observed over a century following an emission of given magnitude in year 1 . The emission of $1 \mathrm{GtC}$ in year 1 has the immediate effect of raising atmospheric $\mathrm{CO}_{2}$ by $0.47 \mathrm{ppm}$. Since some of that carbon is subsequently absorbed by ocean and terrestrial sinks, the 
Figure 5. Increase in Atmospheric Carbon Concentration Following a One-Gigaton Carbon Emission

Parts per million

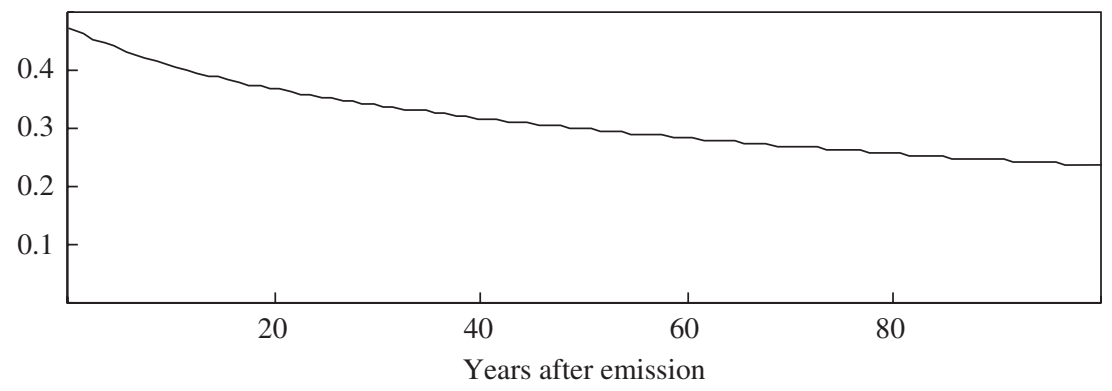

Source: Authors' fit to an impulse response taken from Kheshgi (2004).

increase in atmospheric concentration in response to this 1-GtC increase subsequently declines, as shown in the figure. By year 50 the increase in the atmospheric concentration has fallen to $0.30 \mathrm{ppm}$, and by year 100 to $0.24 \mathrm{ppm}$ (half of the initial impulse).

Given this impulse response function, we can project the century-long change in carbon concentrations. Total carbon emissions and estimated atmospheric carbon concentrations for 2002-2100 are shown in figure 6 . Carbon emissions rise roughly in proportion to total energy use, and the stock of atmospheric carbon rises gradually with each year's carbon emissions, dependent on the unit response function linking emissions to atmospheric carbon concentrations. As shown in the top panel of the figure, in the baseline trajectory fossil-fuel-based emissions rise from the current level of around $5.8 \mathrm{GtC}$ a year in 2002 to $17.0 \mathrm{GtC}$ a year in 2050 and $26 \mathrm{GtC}$ a year in 2100 . As the bottom panel shows, this steep increase in emissions leads to dangerous concentrations of atmospheric carbon by 2050 , reaching $554 \mathrm{ppm}$, on the way to a more than tripling of the preindustrial carbon concentration by 2100 , at $886 \mathrm{ppm}$.

The oil scenario underpinning the baseline is unrealistic, however. Total annual global oil demand is projected to grow from 159 quadrillion BTUs (quads) in 2002 to 477 quads in 2050. This is equivalent to an increase from 78 million barrels of oil equivalent a day to 230 million barrels a day by 2050 . Cumulative oil use between 2002 and 2050 in this scenario is 
Figure 6. Carbon Emissions and Atmospheric Carbon Concentration in Baseline Scenario, 2002-2100
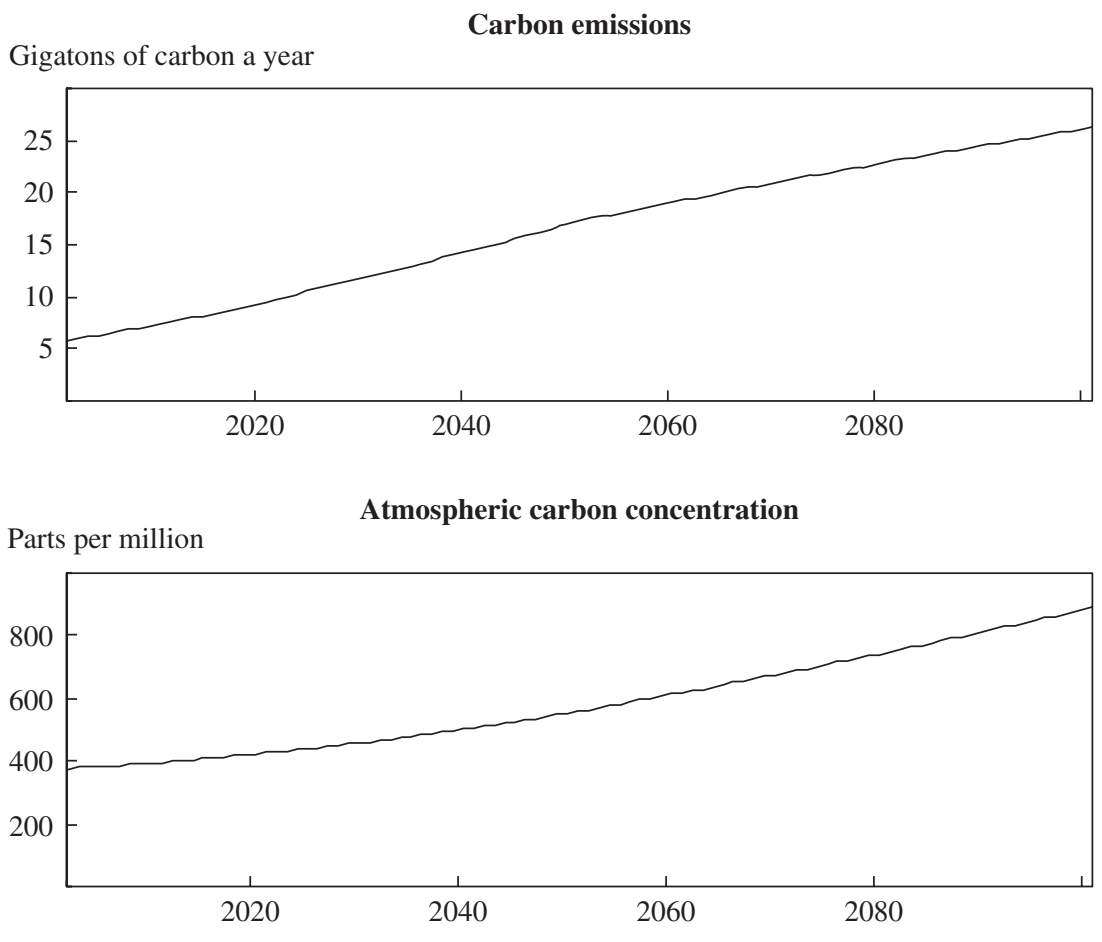

Source: Authors' projections.

around 350 billion metric tons of oil equivalent, which, according to Rogner, ${ }^{78}$ exceeds all of the world's estimated conventional oil resources (proven reserves plus resources yet to be developed). The most pessimistic assessments believe that the world will reach peak production within the next decade; less pessimistic projections put the peak at twenty to thirty years hence. Few observers believe that traditional oil (and natural gas) could satisfy a threefold increase in the rate of oil use between now and 2050 .

78. Rogner (1997). 


\section{Growth in Carbon Concentration if Other Fossil Fuels \\ Substitute for Oil}

If the increased quads of energy are supplied by coal and nonconventional fossil fuels (tars and shale) rather than oil, this implies a massive scaling up in the use of these alternative fuels. Suppose, as an illustration, that peak oil is reached in 2010 at 196 quads a year (roughly 96 million barrels a day). Oil is then assumed to stay at that plateau over the following decades until 2050. Suppose as well that the excess demand for oil is met by coal through the Fischer-Tropsch process. Total use of coal would then rise from 98 quads in 2002 to 574 quads by 2050 . Cumulative consumption of coal between 2002 and 2050 would be around 220 million metric tons of oil equivalent, well below Rogner's resource estimates of 2.4 billion metric tons of oil equivalent. ${ }^{79}$ The key conclusion is that worldwide stocks of coal are very likely large enough to accommodate this demand.

With current technologies, coal is not only highly polluting (producing large amounts of nitrous oxides, sulfur oxides, and mercury) and often highly disfiguring of the mine site, but also a greater emitter of $\mathrm{CO}_{2}$ per unit of final energy than oil or natural gas. Roughly speaking, each quad of coal produces 85 million metric tons of $\mathrm{CO}_{2}$ emissions, compared with 57 million metric tons for oil and 41 million metric tons for natural gas. As a result, an alternative scenario in which oil peaks in 2010 and coal picks up the slack results in 13 percent higher emissions per year as of 2050 compared with the baseline.

The scaling up of coal to substitute for a large part of the projected increase in demand for oil therefore will require two very large scale investments. The first is a major scaling up of Fischer-Tropsch factory operations. This is reportedly already under way in China, although the extent of investment is not known and the public discussion of China's strategy in this regard has hardly begun. Second, the much greater emissions from coal would translate into an even steeper trajectory of $\mathrm{CO}_{2}$ concentrations than shown in the baseline, and therefore an even greater urgency in moving to large-scale mitigation options. The increased use of coal and the scaling up of carbon mitigation must go hand in hand.

79. Rogner (1997). 
Growth in Carbon Concentration with Added Oil Demand in the Asian Transport Sector

The needed transition to clean coal and other energy sources may end up being even more daunting than suggested by the baseline scenario for another reason: transport. China and India are currently far below the world's average level of energy use per unit of GNP in transport. The baseline scenario assumes that energy demand in transport will rise roughly fourfold in China and 6.5-fold in India. These are calculated as the projected GNP growth rates net of the assumed reduction in energy intensity in each sector of 1.5 percent a year. Yet demand for energy in transport may grow much faster than this because the income elasticity of demand for automobiles is likely to far exceed 1 in both China and India. China had a mere 5 million passenger automobiles in 2002 (4 per 1,000 persons). An eightfold increase (in line with GNP growth) would leave China with just 40 million automobiles (roughly 28 per 1,000 persons) as of 2050. That would be far below today's density of automobiles in the United States and Western Europe (675 and 495 per 1,000, respectively), despite the fact that China is assumed as of 2050 to have an income per capita commensurate with that of Europe today. A more reasonable projection would put China on a much-faster-than-income trajectory to catch up in automobile ownership.

The implications of a massive automobile boom in China would be enormous. Suppose, as an alternative to the baseline scenario, that by 2050 China has 235 automobiles per 1,000 population, still less than half the current Western European density. That would mean an extra 288 million automobiles compared with the baseline. Suppose further that new automobiles in China today average 30 miles to the gallon, and that this mileage is improving at the rate of 1.5 percent a year assumed earlier. This would imply an average mileage of $59 \mathrm{mpg}$ by mid-century. If these vehicles are driven an average of 13,000 miles a year (using the standard assumption for U.S. modeling), in 2050 they would require 63.4 billion gallons of gasoline, or 1.5 billion barrels of oil, a year. That in turn translates into 0.6 billion tons of $\mathrm{CO}_{2}$ emissions a year. If we similarly assume that India reaches an automobile density of 235 per 1,000 persons, we must add another 281 million vehicles in India compared with our earlier baseline, which also adds roughly an extra 0.6 billion tons of $\mathrm{CO}_{2}$ emissions a year. 


\section{Global Emissions and the Developing Countries}

The Kyoto Accord divides the world between Annex I countries, comprising the developed and transition economies, and Annex II countries, consisting of China, India, and the rest of the developing world. The premise of the agreement was that only the developed (and transition) economies should be bound by carbon limits in the first phase (up to 2012), so as not to impede the growth prospects of the developing nations. A more efficient approach would have been to bind all countries to a common standard (such as a common carbon tax or a global system of tradable permits) in order to minimize the global costs of reducing $\mathrm{CO}_{2}$ emissions to any target level, and then for the rich countries to compensate the poor countries, to manage the equity issues. In any event the practical consequences of excluding the Annex II countries were deemed modest, given the predominant share of the rich countries in total global emissions.

The simulations highlight the central fact that, to the contrary, today's developing countries will soon produce more than half of total emissions, with their share rising markedly in coming decades. The Annex I countries accounted for roughly 59 percent of total emissions in 2002. This is projected to fall to 50 percent in 2013 in the baseline simulation. By 2025 today's developing countries account for almost 60 percent of the emissions, and this rises to 70 percent in 2050 and 78 percent by the end of the century. (Note that today's developing countries have 81 percent of the world's population today and are expected to have 86 percent by the century's end.) The Kyoto Accord may set a useful framework for beginning to manage carbon emissions, but it does very little in and of itself to limit the rise of carbon emissions and concentrations, since it excludes the part of the world that will soon account for the bulk of emissions.

Nor can the carbon conundrum be solved by slashing growth in the United States while allowing the poorest to catch up. Suppose that the U.S. long-term growth rate were to fall by half, to just 0.8 percent a year. Instead of reaching $\$ 75,000$ in 2050, U.S. income per capita would reach $\$ 51,000$. Even this decline would not prevent the breach of the $\mathrm{CO}_{2}$ doubling threshold, which would then occur in 2066 rather than 2051 as in the baseline. The point is that rising energy use in the developing world, consistent with the convergent economic growth of these countries, now marks the dominant driving force behind rising carbon emissions and concentrations. 


\section{Effects of Implementing Low-Cost Options for Managing Carbon}

Growth in carbon emissions can be slowed by sharply reducing all inputs of primary energy in the world economy, but short of an accompanying breakthrough in technological progress, such a comprehensive restriction in energy use could bring about a sharp and costly break in global economic growth. The losers would most likely be the poorest and weakest countries, which in effect would be told that there is "no room at the inn" for them in light of the approaching global environmental limits. The policy goal, of course, is to find relatively low cost solutions that preserve the option for the poor countries to catch up economically, while respecting the atmospheric budget constraint on emissions.

The dominant impulse of the Bush administration has instead been to wait for something to turn up. Perhaps just the right low-cost technology will indeed be found that allows output to grow with little additional input of primary energy, or perhaps a plentiful and elastic supply of a noncarbon fuel will be discovered, or the world will learn how to capture and dispose of carbon at little cost. Each of these is possible. What is not logical, however, is to do nothing while waiting for one of these, or something else, to turn up.

Delay poses three problems. First, emissions continue to cumulate, bringing the world closer to undesirable carbon thresholds. Second, mitigation is considerably cheaper in new investment projects, rather than retrofitting. Low-cost mitigation will therefore require a very long lead time, which means it should be started sooner rather than later. Third, mitigation technologies are likely to exhibit a powerful learning curve, in which the marginal costs of mitigation are likely to bear an inverse relation to cumulative investments in such activities.

Given the importance of moving quickly where feasible, in view of the risk of rapidly rising carbon concentrations in the coming decades, two scalable, low-cost technologies present themselves. The first is gasolineelectric hybrid automobiles and trucks, which use a proven and operational technology that, as discussed above, could dramatically raise gasoline mileage and thereby reduce carbon emissions in the transport sector, which currently accounts for roughly one-third of total U.S. emissions.

HYBRID AUTOMOBILES. Current hybrid technologies allow an approximate doubling of fuel efficiency from roughly 25 miles to the gallon to 
50 or more for mid-sized sedans. ${ }^{80}$ Trucks and sport utility vehicles (SUVs) can similarly be outfitted with hybrid technology. Several of the lackluster performance characteristics of hybrids, such as power in acceleration, are rapidly improving, so that the performance costs of the vehicle are diminishing or being eliminated entirely. The net social costs of a transition to hybrids depend on the cost of fuel. A typical U.S. passenger vehicle, as noted earlier, is driven an estimated 13,000 miles a year. At 25 miles to the gallon, this is 520 gallons a year. A hybrid that achieves 50 miles to the gallon reduces this figure by half, to 260 gallons a year. With a barrel of oil costing, say, $\$ 50$, the price (excluding tax) of gasoline is therefore approximately $\$ 1.20$ a gallon, so that the annual saving in gasoline outlays equals $\$ 312$.

The extra cost of manufacturing a hybrid compared with a comparable standard vehicle is difficult to assess with precision and is changing over time. A 2001 estimate by the Argonne National Laboratory put the extra cost at around $\$ 4,000$, depending on the model specifications. ${ }^{81}$ In 2004 the premium on hybrids to the customer was around $\$ 2,500$ to $\$ 4,000 .{ }^{82}$ Of course, with larger production runs and learning by doing in their manufacture, the cost of hybrids could come down considerably. ${ }^{83}$ To illustrate the trade-offs of capital costs versus fuel efficiency, suppose that the extra capital and maintenance outlay on a hybrid vehicle is $\$ 3,000$ in present value (which is probably at the high end of the likely range given increased future competition, increased scale of production, and technological advances, all of which can be expected). If we further assume annual savings of gasoline equal to $\$ 312$, the hybrid achieves total savings with a net present value of $\$ 400$ for a vehicle that lasts fifteen years. (All present value calculations in this paragraph and the next assume a discount rate of 5 percent.) From the consumer's point of view, the savings are even greater, since the consumer pays for gasoline inclusive of taxation, which roughly

80. See U.S. Department of Energy fuel efficiency data at www.fueleconomy.gov. The Toyota Prius is estimated to get 60 miles to the gallon in city driving and 51 miles to the gallon on the highway.

81. See Plotkin and others (2001).

82. See D. Welch and others, "Gentlemen, Start Your Hybrids," Business Week, April 26, 2004.

83. See D. Welch and C. Dawson, "Itching to Ditch the Slow Lane," Business Week, April 26, 2005, on improving battery technology in hybrid cars. 
doubles the overall price per gallon and therefore doubles the savings in fuel cost to the consumer.

From a policy point of view, hybrids should be subsidized relative to nonhybrids through implicit or explicit subsidies to take into account the reduction in carbon emissions. Each gallon of gasoline emits approximately 19.6 pounds $\left(8.9 \mathrm{~kg}\right.$ ) of $\mathrm{CO}_{2}$. If each hybrid saves 260 gallons of petroleum a year, the reduction in carbon emissions per vehicle per year is about 2.3 metric tons. At a carbon price of, say, $\$ 50$ a ton, the annual value of this carbon reduction is $\$ 115$, for a present value of $\$ 1,250$ over the vehicle's life. This could be remitted to the consumer through a direct tax concession on hybrid purchases (as now applies in the United States for a limited number of sales per company) or through a saving on emissions permits or carbon-based taxes if these are eventually levied. In short, the existing hybrid technology can substantially reduce carbon emissions at no significant economic cost. Presumably, the technology will also continue to improve through learning by doing, as has been occurring rapidly in recent years.

Suppose that the entire world vehicle fleet is converted to hybrids as old models are worn out and scrapped. We assume that one-twentieth of the fleet turns over each year beginning in 2006, so that by 2026 the entire fleet would be using hybrid technology. To be specific, we assume that, in the baseline scenario, all vehicles begin at an average of 21 miles to the gallon in 2002 (averaged across passenger cars, light trucks and SUVs, and heavy trucks). Without hybrids, the world's fleet experiences a gradual improvement in fuel efficiency of 1.5 percent a year, reaching $42 \mathrm{mpg}$ by 2050 . The total hybrid fleet, we assume, averages 42 miles to the gallon in 2002, and it too achieves a gradual improvement of 1.5 percent a year. The hybrid fleet gradually replaces the nonhybrid fleet over a period of twenty years, so that annual global fleet performance is a weighted average of the nonhybrid and hybrid fleets. We assume that by 2026 all vehicles are hybrids (or use comparably efficient technology), averaging 60 miles to the gallon in that year, rising to 87 miles to the gallon by 2050 .

The new scenario reduces the atmospheric $\mathrm{CO}_{2}$ concentration in 2050 from $554 \mathrm{ppm}$ in the baseline simulation discussed above to $534 \mathrm{ppm}$. As we have already seen, the economic costs are likely to be negative with oil at $\$ 50$ a barrel, with the fuel savings outweighing the added capital costs of the hybrid. The exact savings, which we do not estimate, would depend on the long-term costs of the hybrid technology (especially the batteries), 
consumer driving patterns, and the cost of energy. The global cost savings would depend on the size of the automobile fleet in India and China, which, as already noted, may be far larger than implied by the baseline.

CARBON CAPTURE AND SEQUESTRATION. The second major innovation that offers reasonably low cost and large potential scale is CCS. As noted earlier, there is a scientific consensus that enough geological sites exist worldwide to store at least 2,000 Gt of $\mathrm{CO}_{2},{ }^{84}$ enough to last for more than a century, although leakage rates are still unknown. The costs of this operation are surprisingly modest and can be fairly reliably estimated, since all of the relevant operations (separation of the $\mathrm{CO}_{2}$ from the exhaust gases, transmission by pipeline, and geological storage) involve known and proven technologies.

The basic trade-off for these gains is an additional capital expense in the construction of the power plant and the pipeline to carry the $\mathrm{CO}_{2}$ to the site of geological deposition, plus a higher input of fuel, since some energy must be used for the capture, transmission, and storage of the $\mathrm{CO}_{2}$. With an appropriate new coal-fired plant using an appropriate technology (such as IGCC), the estimated added capital cost for carbon capture is roughly between $\$ 245$ and $\$ 705$ per kilowatt, ${ }^{85}$ which is approximately equivalent to $\$ 0.0035$ to $\$ 0.01$ per kilowatt-hour on an annualized basis.

In addition, the required energy input is raised by approximately 20 percent. Consider, therefore, the added costs of CCS for 1 billion kWh of delivered electricity. One trillion kilowatt-hours of power is equal to 3.4 quads. Non-CCS coal-fired power plants operating at a typical efficiency of 0.35 would require 9.7 quads of thermal input from coal to deliver that amount of power. With roughly 1 billion short tons of coal needed to produce 20 quads (depending on the heat content), 1 billion $\mathrm{kWh}$ of electricity requires 0.480 million short tons of coal. The price of a short ton at this assumed heat content is around $\$ 30$. Therefore the total annual coal input price is roughly $\$ 14.4$ million, or $\$ 0.014$ per kilowatt-hour. The additional 20 percent coal input required for CCS thus costs about $\$ 0.003$ per kilowatt-hour. Adding this to the capital costs, the total costs of $\mathrm{CCS}$ at the power plant are estimated to be between $\$ 0.007$ and $\$ 0.012$ per kilowatt-hour. When we add to this the estimated costs of pipeline transmission and geological storage, the total costs of CCS are estimated to be 
in the range of $\$ 0.01$ to $\$ 0.03$ per kilowatt-hour for an IGCC power plant ${ }^{86}$ The avoided carbon emissions are estimated to be 0.6 to $0.7 \mathrm{~kg}$ of $\mathrm{CO}_{2}$ per kilowatt-hour.

By 2050, under the baseline simulation, electricity demand will be around 132 quads, or 38,800 billion $\mathrm{kWh}$. Of this, around 28,000 billion $\mathrm{kWh}$ is projected to be produced in fossil-fuel-fired plants, mainly coal-fired plants. At a cost of CCS of between 1 and 3 cents per kilowatt-hour, this translates into a total added energy cost as of 2050 of $\$ 280$ billion to $\$ 840$ billion. Since gross world product in 2050 is estimated in this scenario to be $\$ 277$ trillion, the costs of CCS are between 0.1 and 0.3 percent of gross world product. The savings in emissions would be around $17 \mathrm{Gt}$ of $\mathrm{CO}_{2}$ a year in 2050. The cost of avoided emissions is therefore roughly between $\$ 16$ and $\$ 49$ a ton.

If we assume that CCS is introduced linearly in all fossil-fuel-powered electric power plants during the period 2006-36, the atmospheric $\mathrm{CO}_{2}$ concentration in 2050 is reduced from the baseline of $554 \mathrm{ppm}$ to $508 \mathrm{ppm}$. If both CCS and hybrid automobile technologies are phased in beginning in 2006 (with twenty years for the hybrids and thirty years for the power plants), $\mathrm{CO}_{2}$ concentration in 2050 falls to $488 \mathrm{ppm}$, at a cost of under 0.3 percent of gross world product in that year. If, in addition, CCS is phased in at large industrial installations outside of the power sector, the concentration in 2050 could be reduced further, to perhaps $478 \mathrm{ppm}$.

\section{Beyond 2050}

Together, CCS and a switch to hybrid vehicle technology (followed by continuing improvements in automobile performance to around 100 mpg by 2050) are powerful enough interventions in themselves to limit emissions to below $500 \mathrm{ppm}$ by mid-century. They do not, however, come close to stabilizing atmospheric carbon. If we project (heroically) to 2100 , assuming continued population and economic growth along the convergence threshold, continuing U.S. economic growth at 1.7 percent per capita, and continuing reductions of energy intensity in all sectors at the rate of 1.5 percent a year, the atmospheric $\mathrm{CO}_{2}$ concentration still reaches 688 ppm by 2100. Clearly, deeper technological change will be

86. See Metz and others (2005, table TS.10, p. 40) for a description of an IGCC power plant. 
needed to support a century-long process of population growth and convergence in incomes.

The main challenges to the post-2050 environment would then be the point-source emitters of $\mathrm{CO}_{2}$, that is, buildings, vehicles, and industrial sites that use fossil fuels on too small a scale for capture and sequestration. The fundamental technological strategy in such settings would be to identify low-cost alternative noncarbon energy carriers that can substitute for the point-source uses of fossil fuels. Two are obvious. The first is electrification of functions currently powered by local combustion. Heating of homes and buildings, as noted earlier, could substitute efficient heat-pump technology for the use of local boilers. The second technological option would be to substitute a noncarbon fuel as a carrier, for example hydrogen, which could be produced largely by fossil fuels at plants large enough to undertake CCS. In essence, all uses of fossil fuels would be centralized at plants that can undertake CCS, and all point-source energy users would be converted to electricity or another noncarbon energy carrier. This further technological conversion could permit a nearly zero-emissions world economy by the end of the twenty-first century. Of course, by that time other economical, nonfossil primary energy sources-most notably, solar and nuclear technologies-might in any event have substituted substantially and economically for the use of fossil fuels.

\section{Next Steps}

The most striking fact about the costs of mitigation is not their absolute magnitude, but rather their distribution. Most of the reduction in carbon emissions will take place in the developing countries, even though most of the increase in atmospheric $\mathrm{CO}_{2}$ to this point is due to emissions in the high-income countries. The logic of cost minimization says that low-cost mitigation technologies (such as CCS or hybrid automobiles) should be installed in every country, rich or poor, as the opportunity arises. The logic of equity, however, holds that the extra costs should be borne by the rich countries, not the impoverished countries, not only because they are poor, but mainly because they contributed little to the climate problem until now.

In practical terms the single most urgent step is for the United States and Europe to work together with the two coal giants, China and India, to make the transition to CCS technology. Part of the incremental costs in China and India should be borne by the high-income countries. If China, India, Europe, and the United States would indeed commit to implement- 
ing CCS at all future power plants and large fossil-fuel-using industrial facilities, the world would take a huge step toward large-scale carbon mitigation. If all four regions would simultaneously commit to greatly improved standards on future vehicles, the combined action would dramatically reduce global climate risks.

Economic logic suggests that these goals could best be accomplished through a uniform tax on carbon emissions imposed on all fossil-fuel users in all regions, or by a global tradable permits system. But both approaches might prove to be administratively or politically impossible to implement. It might be easier in the end to focus on the much smaller number of decisionmakers involved in licensing new power plants and setting future automotive efficiency standards. If all power plants around the world were required to be (at least) as carbon-free as CCS coal-fired plants, and if all automotive fleets were required to meet a common fuel efficiency standard to be phased in over many years, a decisive reduction of carbon emissions could be achieved without the administrative burden of a complex trading system. On the other hand, the market signals to encourage the development of new, alternative, carbon-free technologies would be muted.

\section{The Urgency of $R \& D$}

Of course, the feasibility of low-cost mitigation as recommended here is predicated on the future success of CCS and hybrid vehicle technologies. This success is likely but very far from assured. The physical leakage rate of carbon storage, as stressed earlier, remains a great issue. The resilience and performance of hybrids are still up for grabs. History has shown that it is prudent not to put all one's eggs in one technological basket under any circumstances, and not to count on further breakthroughs in efficient carbon management, energy efficiency, and renewable energies. In addition to implementing practical steps with the technologies at hand, or nearly at hand, it will also be crucial to step up public and private research and development on alternative energy systems, especially solar power, capable of delivering large-scale and longterm-sustainable energy. 


\section{Comments and Discussion}

Richard N. Cooper: I agree strongly with the main conclusion of this paper by Klaus Lackner and Jeffrey Sachs, which is that there is no shortage of energy on the horizon. The paper rightly emphasizes the substitution possibilities among different forms of energy, even at today's technology, and the abundance of total energy. The debate over the prospective exhaustion of liquid fuels takes many forms, but most are based on false premises, as the paper usefully points out. The authors also argue that the world faces a serious problem in climate change, or, as they put it more generally, in the environmental constraints on energy use, and that it must be dealt with as quickly as possible. Furthermore, solutions are actually at hand with existing technology or are within reasonable sight, so there is some basis for dealing with the problem.

The paper is an unusual one for a Brookings Papers panel. It is largely a primer on the role of energy in modern society, with a main emphasis on technology and technological possibilities. There is a fair amount of catalytic chemistry here, and some physics as well. Readers will have to brush up on their high school chemistry.

The paper performs a great service in being quantitative. This is, after all, essentially a quantitative topic. One cannot talk sensibly about energy alternatives without quantifying the possibilities. There are many attractive ideas out there, such as wind power, but when one looks quantitatively at the possibilities for mobilizing them, it is clear that many can play only a niche role. The authors' focus on magnitudes is thus very useful in dispelling some myths or, more accurately, some wishful thinking. In this connection, however, I missed a more complete discussion of one potentially important technology, namely, the making of liquid fuel from biomass, both biomass 
grown for the purpose (and thus competing for land with food producers) and, more important, waste biomass such as corn stalks.

The intellectual framework of the policy parts of the paper involves stipulating some ceiling for atmospheric greenhouse gas concentrations, mainly $\mathrm{CO}_{2}$. This threshold is not specified but is assumed to lie somewhere between two and three times the preindustrial concentration of about 280 parts per million. Thus the authors explicitly reject a cost-benefit approach to climate change, such as that developed by William Nordhaus, in effect assuming that the costs of climate change (and hence the benefits of mitigating it) become infinite beyond the ceiling. This assumption, I suspect, drives their call for early action.

The paper constructs a baseline, "business-as-usual" scenario for greenhouse gas emissions over the next century on the basis of an assumed convergence of income per capita around the world on income per capita (or some fraction thereof) in the United States, which itself continues to grow: the gap is narrowed at a steady pace of 2 percent a year. This does not sound unreasonable until one realizes that, along with the authors' other assumptions, it implies a growth in global income per capita of 3 percent a year until 2050. This compares with 2.1 percent a year during the half century 1950-2000. On historical experience, then, 3 percent is implausibly high. The implausibility is increased by using purchasing power parity (PPP) to calculate national and hence global GDP, so that the starting point is gross world product of $\$ 46$ trillion in 2002, instead of the $\$ 31$ trillion measured at market exchange rates. PPP, which, in effect, values output everywhere in the world at U.S. prices, gives much greater weight to agricultural output than does pricing at market exchange rates. Since agriculture, which accounts for a large share of output in poor countries, typically grows more slowly than other sectors, giving it greater weight implies lower growth rates than the world is accustomed to. And calculated over a century, or even half a century, even small differences in growth rates can make a big difference. Applying the authors' assumed energy elasticity of 0.55 to a more reasonable annual growth in world income per capita of 1.8 percent (implying, with annual average population growth of 0.8 percent, an annual growth in gross world product of 2.6 percent, compared with the authors' 3.8 percent) would lead to $\mathrm{CO}_{2}{ }^{-}$ equivalent carbon emissions of 11.6 billion tons by 2050, compared with 17.0 billion in the authors' baseline, and 5.9 billion tons in 2002. Atmospheric concentrations of $\mathrm{CO}_{2}$ by 2050 would then be under $500 \mathrm{ppm}$, 
rather than the $554 \mathrm{ppm}$ in the authors' baseline; the figures for 2100 would also be significantly lower.

This adjustment does not, however, materially alter the authors' policy conclusions, given their focus on the need to avoid crossing a specified threshold; at best it provides a little more time. And, as the authors point out, in at least two respects their baseline projection is a conservative one. If coal liquefaction must take place earlier than they assume because of a more rapid depletion of conventional oil, or if automobile use in China, India, and other growing countries rises more rapidly than they assume, emissions will be higher.

The paper places heavy emphasis, as does the current U.S. administration, on the sequestration of $\mathrm{CO}_{2}$, especially from power plants and other concentrated users of fossil fuels. Given the abundance of coal in the United States, China, and India, this is probably an appropriate emphasis for the next half century, and perhaps beyond. The authors suggest that the all-inclusive cost of carbon capture and storage (CCS) would be in the range of 1 to 3 cents per kilowatt-hour of electricity in an appropriately designed plant, raising the busbar cost of electricity (that is, the cost before distribution) by perhaps 50 percent. It is unclear where this and other cost estimates in the paper come from; this one seems to be on the optimistic side. But the fact is that one cannot know how much it will cost until it is tried on a commercial scale, on which more below.

Costs are relevant, since, as the authors observe, nuclear power is an available alternative that does not emit greenhouse gases. Nuclear power has been economically unattractive in the United States during the past two decades, in part because of regulatory and legal delays and uncertainties. But with newer, standardized nuclear plants currently under design and a 50 percent or more increase in the cost of electricity from coal-fired plants, the economics of nuclear power could become much more attractive, especially in other countries but even in the United States.

Two problems of concern with nuclear power are how to store high-level nuclear waste (especially spent fuel rods) and the possible misdirection into nuclear weapons of the plutonium in spent fuel. I have never understood why so much effort has been directed at finding so-called permanent storage for nuclear waste; I would instead continue indefinitely the "temporary" storage used to date, which places the waste in secure, well-guarded concrete bunkers, where the containers can be watched and repaired if they corrode unexpectedly, and where the still considerable energy contained 
in them can be used if future generations discover how to do it economically and safely. The possible misuse of spent fuel for extraction of plutonium needs to be addressed through international agreement on a much tighter beginning-to-end nuclear fuel cycle than now exists. This will not be easy, but secure use of nuclear power depends on creating such a system, building on the current nonproliferation regime.

When it comes to CCS, as the authors note, it will be much more expensive to retrofit an existing plant than to design and build a new plant with CCS in mind. Once a large power plant is built, it will last for forty to sixty years. That argues for starting seriously, and soon, to include CCS in the design of all greenfield coal-fired power plants.

The most active frontier now, when it comes to $\mathrm{CO}_{2}$ emissions, is China. China builds over a gigawatt a week in new power capacity, 70 percent of it fueled by coal. China also has an aggressive program for nuclear power, an aggressive program for importing liquefied natural gas, and an aggressive program for hydroelectric power. The Three Gorges Dam, when the reservoir is completely filled in 2009 , will generate 18 gigawatts of electric power. That is the equivalent of eighteen big nuclear plants or eighteen huge coalfired plants.

But even with all that new capacity, China's demand for power is growing so rapidly that still more will be needed. The new coal-fired capacity that China is expected to install in the coming two decades exceeds what is projected for the United States and Europe together. In short, China is where the action is, and therefore that is where the focus on limiting climate change needs to be. China's new plants should be built with sequestration designed in. China will not agree to incur the extra costs; they will have to be incurred by the rich countries, especially the United States. And CCS is a promising but unproven technology. China's rapid construction program should be seen as a testbed for various ideas, to discover the most cost-effective way to sequester carbon, so that the technology can then be applied elsewhere as well.

The focus of this paper is on climate change and, implicitly, on other environmental issues. But energy security is also an important issue. The world's growing dependence on the Persian Gulf for oil creates many misgivings. Thus, whereas the focus for climate change is coal, the focus for energy security is oil. The two policy objectives-mitigating climate change and ensuring energy security—run in parallel only a certain distance, and then they separate. Carbon sequestration, if the price can be brought down 
to 1 to 3 cents a kilowatt-hour, brings the two together, because coal liquefaction then becomes a viable substitute for oil. So that is another reason to develop sequestration.

The paper observes that although the Kyoto Protocol is a "useful framework" for beginning to manage carbon emissions, it cannot do the job alone. The authors are too generous to the Kyoto Protocol. My own view is that it will divert attention from seriously addressing this issue for ten to fifteen years. The sooner we move beyond its framework, which cannot seriously reduce greenhouse gas emissions, the better.

My recommendation is a global carbon tax, as a charge for the negative externality of $\mathrm{CO}_{2}$ emissions. Such a tax, which would be agreed upon internationally, but collected nationally, would encourage emissions-reducing actions across the board. I do not suggest that it would be easy to install, but the effort should get under way as soon as possible, and even if it does not succeed, the debate will bring global attention to the issue of climate change and shift the focus much more sharply toward those technologies that are likely to be productive.

William A. Pizer: Klaus Lackner and Jeffrey Sachs present a compelling case for worrying about future energy needs. They draw attention to an inevitable collision between the world's insatiable thirst for cheap energy and the increasingly threatening accumulation of carbon dioxide in the atmosphere. In turn, they use this collision to argue for two promising technological solutions over the next fifty years: $\mathrm{CO}_{2}$ capture and storage from stationary sources coupled with gas-electric hybrid vehicles. On a 100-year scale, they argue that the further use of electricity and hydrogen as energy carriers to replace fossil energy use at smaller sources (such as residential buildings and vehicles) will be the obvious technological solution. To move in this direction, they recommend that Europe, the United States, China, and India work together to ensure that future power plants meet a CCS emissions standard and that vehicle fleets meet more stringent efficiency standards. While noting the economic efficiency of tradable permits or taxes to achieve these ends, they suggest that a more practical alternative would be a performance standards approach.

I tend to agree with most of Lackner and Sachs' main points. In particular, I believe a coming collision between global energy needs and concerns over global climate change is increasingly apparent. I also believe that CCS and hybrid vehicles are particularly promising technologies. And I believe that 
collaboration among Europe, the United States, China, and India is likely to be a more fruitful avenue for action than the existing United Nations framework and that technology policies (as distinguished from marketbased approaches) could play a useful role.

Where I principally disagree is, first, with their intensive focus on CCS and hybrid technologies and, second, with their haste in dismissing marketbased policies in favor of sector-based performance standards. My feeling is that the potential for nuclear power and renewable energy sources warrants a more balanced technological approach and, similarly, that technology policy should be viewed as a complement to a market-based approach, not a substitute for it. I also have a more subtle, almost philosophical disagreement with their overall framework, which tends to ignore the question of reasonable mitigation costs in favor of a laser-like focus on achieving zero net emissions by the end of this century.

Before addressing the paper's policy recommendations, however, I would note that the first third of the paper provides an excellent synopsis of global energy demand, global energy supply, and global environmental concerns. The main points of this portion of the paper are nicely summarized in the introduction: First, global economic growth will lead to increases in primary energy demand that are too large to be avoided through increases in energy efficiency. Second, there are no serious limits on fossil fuel supply over the next century, given the convertibility of coal into gas and liquid forms. Third, rising atmospheric concentrations of carbon dioxide from the combustion of fossil fuels pose a serious environmental threat-hence the collision of energy needs and environmental concerns.

Where I begin to diverge is with the authors' winnowing of promising technologies down to an almost exclusive focus on CCS and hybrids. While not ruling out other technologies-they suggest, for example, a performance standard for power plants that could be met by nuclear or renewable fuels - they spend little time discussing these alternatives and the policies that might move them along. For example, they note that proven uranium reserves would be used up in a matter of decades if the global energy system went 100 percent nuclear. Yet a recent study by the Massachusetts Institute of Technology points out that increases in prices would likely produce significant increases in proven uranium resources,

1. Deutch and others (2003). 
as occurs with virtually all mineral resources. ${ }^{1}$ One estimate suggests that a doubling of current uranium prices would produce enough supply to meet current global demand for fifty years. The same MIT report makes a host of practical suggestions, particularly surrounding waste and proliferation management, to expand the role for nuclear energy.

The paper contains virtually no discussion of renewable energy sources, of which cellulosic ethanol and biodiesel are particularly promising. For example, a recent study by the National Commission on Energy Policy demonstrated that replacing half of oil demand with biofuels would have the same environmental impact as a doubling of fuel economy standards. ${ }^{2}$ Meanwhile the comparative political feasibility of renewable fuels versus increased fuel economy is evident in the energy bill enacted in 2005, which established a 7.5-billion-gallon renewable fuels standard starting in 2012 while ignoring fuel economy altogether.

Also, the costs of CCS and hybrids may not be as low as Lackner and Sachs suggest. In the case of CCS, they note that expenditures would amount to between 0.1 and 0.3 percent of gross world product, but they do not mention that the cost per kilowatt-hour amounts to a 15 to 45 percent increase in average U.S. electricity prices. In the case of hybrid vehicles, the authors estimate a positive net present value, relative to conventional vehicles, of $\$ 400$ for a hybrid vehicle lasting sixteen years. But their analysis excludes the potential cost of replacing the battery $(\$ 2,000$ to $\$ 3,000)$, uses a somewhat favorable discount rate and vehicle life (cars do last a long time but tend to be driven less as they age), and, perhaps most important, ignores the marginal net benefits of such a standard. Even if the average net benefits are positive, the marginal net benefits of doubling fuel economy are likely to be negative, perhaps significantly so.

None of this is meant to argue that CCS and hybrid technologies are not important, or even that they are not the leading technologies. Nor is it meant to suggest that such technologies should not be pursued because they may be more expensive than Lackner and Sachs indicate. However, they are just two among perhaps a half-dozen competing technologies, such as nuclear and renewable fuels, that may play an important role over the next several decades. 
Ideally, policymakers would avoid having to choose among technologies by simply pricing $\mathrm{CO}_{2}$ emissions, through a tax or tradable permit system, and letting the private sector work things out on its own. Various technologies could then compete without further government involvement. As the authors suggest, however, such policies are politically difficult in many countries. In developing countries especially, it seems unlikely that governments would embrace such policies—indeed, if there was one trend evident at the recent UN meetings on climate change in Montreal, it was developing countries' uniform refusal even to discuss their accepting any form of emissions targets. ${ }^{3}$ Lackner and Sachs suggest sector-based performance standards as a logical alternative and next step.

I would argue, a bit paradoxically, both that such standards at times do not go far enough to avoid political obstacles and that, at the same time, they are too quickly embraced by the authors as an alternative to marketbased policies. On the first point, one needs to recognize the significant obstacles to the performance standards approach in the United States. U.S. automakers oppose improved vehicle fuel economy standards both because of their own disadvantage, relative to their foreign competitors, in meeting them and because of their lack of expertise in hybrid technology, which is largely imported. Therefore a more practical policy-if one is motivated by that concern-is likely to require additional incentives to shift U.S. automobile manufacturing in a more fuel-efficient direction. ${ }^{4}$

In the area of electric power generation, a performance standard seems no more likely to be adopted than a tradable permit system, given the sector's experience and familiarity with tradable permits. Generally, the level of performance standards that Lackner and Sachs describe-a CCS standard for new power plants and a hybrid standard for new vehicles-seems far beyond what any nation is ready to embrace in the near future. Encouraging these technologies will require something more targeted and generous.

Beyond the United States, the enthusiasm of developing countries for a sector-based performance standard seems nearly as low as for an overall emissions target. A more likely scenario may be to develop a way in which climate-friendly policies can feed into market-based policies in industrialized countries. Such an approach was put forward at the Montreal meetings as

3. Aguilar and others (2005).

4. Such an approach was laid out by the National Commission on Energy Policy (2004). 
a possible modification to the Clean Development Mechanism under the Kyoto Protocol.

This leads to my more important concern, which is that Lackner and Sachs fail to emphasize the need for some form of minimal market-based incentive, such as an emissions trading program with a somewhat weak target or price cap. Such an incentive will be useful both to get the right architecture in place as future policies may need to ramp up, and to provide some incentives in those areas where neither the sector- nor the technology-based approach applies. Recent research has emphasized the positive interaction of technology and emissions pricing policies. ${ }^{5}$

All of these concerns relate to a somewhat philosophical question about how the problem should be framed. Lackner and Sachs establish as an imperative the development of a carbon-free future, and this in turn drives their emphasis on specific technologies that appear to be the more obvious solutions. Although they do not abandon a cost-benefit approach, they seem to loosely embrace the notion of a safe target for atmospheric $\mathrm{CO}_{2}$ concentration. They state that this approach is a reasonable one in "a situation where significant ecosystem changes due to anthropogenic climate change are assumed to have large but also unquantifiable consequences on global society." Such an approach pretends that, somehow, it is easier to pick a safe concentration level than to estimate climate impacts and their value. That does not ring true-although there are some threshold effects, many other effects are incremental, and even the threshold effects are notoriously difficult to pin down. If we expend considerable effort to meet an atmospheric $\mathrm{CO}_{2}$ concentration target of 560 parts per million, but horrific effects occur at $550 \mathrm{ppm}$, what have we accomplished? The UN Framework Convention on Climate Change may have embraced the safe target approach for the sake of reaching an international accord, but it does not necessarily make sense (any more than the Clean Air Act's use of ambient air quality standards "to protect the public health" makes sense if dose-response functions are essentially linear). A particularly useful addition to the paper would have been to include mention of recent summaries of estimated mitigation benefits, ${ }^{6}$ which provide a convenient mitigation cost benchmark for various technologies.

5. Fischer (2004).

6. Such as Tol (2005). 
On the whole, Lackner and Sachs argue convincingly that action to address climate change is needed and that CCS and hybrid vehicles have an important near-term role. The weakness of the paper is its failure to address other competing technologies with potentially significant roles. Their policy suggestion to focus on a smaller set of countries and not become overly hung up on market-based policy solutions is also useful; the weakness here is more a matter of detail. They fail to consider the significant value of having even a small market price on carbon and what the non-marketbased policy alternatives might really need to look like. Finally, I find it disappointing that they provide no guidance on benefit estimates and instead emphasize safe concentration targets. To some extent this latter point has little consequence for near-term policies to encourage key technologies. In the broader debate over the design of tradable permit systems and the use of price-like mechanisms, however, such distinctions are important.

General discussion: Following Richard Cooper's suggestion of a global carbon tax, other panelists discussed the need for policies that would lead to achieving the paper's goals. Benjamin Friedman noted that the paper had outlined a number of desirable changes to present practice and technologies, but that its proposals also carried some of the flavor of a command economy. It was not clear, he argued, what specific policies would provide incentives for private endeavor to lead in the directions the paper favored. Alan Blinder agreed but added that there may be no good policy answer for some of the needed changes. No global government exists to impose a global carbon tax, and overcoming the externality appears to be a nearly insuperable problem.

Gregory Mankiw agreed on the need for a global carbon tax and argued that the cap-and-trade system envisioned by the Kyoto Protocol was equivalent, from an efficiency standpoint, to such a tax. However, the cap-andtrade system would inevitably involve cross-national transfers, which would surely create political difficulties, whereas a carbon tax could be imposed by each government individually, and no transfers would be necessary. David Laibson disagreed with Mankiw's suggestion, arguing that the developing countries, especially, would not go along. He agreed with Friedman that the problem was how to design specific, incentive-based mechanisms to achieve the desired goals. What the paper should address is which of various alternative mechanisms would provide incentives for the governments of each of the roughly 200 countries in the world to adopt a carbon tax. Such a mechanism would entail transfers from the developed world, which has the 
greatest interest in the issue, to the developing countries, which can least afford to do anything about it.

To Friedman, the authors seemed quite optimistic about solar energy for the long run, whereas in popular discussion it does not figure as prominently as either fossil or nuclear energy. He asked whether the associated technology is improving and the cost decreasing. Klaus Lackner replied that solar power could potentially provide all the world's energy needs but is very expensive. Mass production could significantly lower the cost, but, beyond that, improved technology would be needed if solar power is to greatly expand its present role.

Blinder remarked on the authors' observation that hybrid automobiles are cost efficient over a fifteen-year life span. Most people replace their cars every three or four years and (although with perfect capital markets this should not matter) tend to behave as if they face extremely high interest rates. This, along with the high cost of replacing the batteries at intervals, Blinder concluded, poses a significant obstacle to the spread of hybrid automobile technology.

Robert Gordon professed surprise on hearing Cooper refer, in his discussion of the paper, to economies of scale in coal-fired power plants as if these were somehow unlimited. Gordon's own recently published study of electric power generating plants had concluded that the industry had reached a plateau of efficiency and productivity in the late 1960s, due both to the constraint of supercritical pressure levels, which act like the sound barrier to limit scale and efficiency, and to the physical constraints imposed by federally mandated scrubbers and other antipollution equipment. Gordon doubted that subsequent technological improvements could have overcome these fundamental barriers. 


\section{References}

Aguilar, Soledad, and others. 2005. "Summary of the Eleventh Conference of the Parties to the UN Framework Convention on Climate Change (UNFCCC) and First Conference of the Parties Serving as the Meeting of the Parties to the Kyoto Protocol." Earth Negotiations Bulletin (December 12).

Anderson, Søren, and Richard Newell. 2004. "Prospects for Carbon Capture and Storage Technologies.” Annual Review of Environment and Resources 29: 109-42 (November).

Andersson, K., F. Johnsson, and L. Strömberg. 2003. "Large Scale $\mathrm{CO}_{2}$ CaptureApplying the Concept of $\mathrm{O}_{2} / \mathrm{CO}_{2}$ Combustion to Commercial Process Data." VGB Powertech 10: 1-5.b.

Archer, David, Haroon Kheshgi, and Ernst Maier-Reimer. 1997. "Multiple Timescales for Neutralization of Fossil Fuel $\mathrm{CO}_{2}$." Geophysical Research Letters 24, no. 4: 405-08.

Barro, Robert J., and Xavier Sala-i-Martin. 1995. Economic Growth. McGraw-Hill.

Bartis, James T., and others. 2005. Oil Shale Development in the United States. Santa Monica, Calif.: RAND Corporation.

BP. 2005. BP Statistical Review of World Energy, vol. 54. London.

Brown, William C. 1984. "The History of Power Transmission by Radio Waves." IEEE Transactions on Microwave Theory and Techniques, Special Centennial Historical Issue MTT-32, no. 9: 1230-42.

Campbell, Colin J., and Jean H. Laherrère. 1998. "The End of Cheap Oil.” Scientific American 278, no. 3: 78-83.

Cess, Robert D. 2005. "Water Vapor Feedback in Climate Models." Science 310, no. 5749: 795-96.

Dahl, Carol A. 1992. "Survey of Energy Demand for Developing Countries." In Energy Modeling Forum, Report 11, International Oil Supplies and Demands. Stanford University (April).

1993. "A Survey of Energy Demand Elasticities in Support of the Development of the NEMS." Prepared for the United States Department of Energy, Contract De-AP01-93EI23499. Washington (October).

Damuth, John. 1991. "Of Size and Abundance.” Nature 351, no. 6324: 268-69.

Deffeyes, Kenneth S. 2001. Hubbert's Peak: The Impending World Oil Shortage. Princeton University Press.

Deutch, John, and others. 2003. The Future of Nuclear Power: An Interdisciplinary MIT Study. Massachusetts Institute of Technology.

Energy Information Administration. 2004a. International Energy Annual 2002. Washington (June).

2004b. Emissions of Greenhouse Gases in the United States 2003. Washington: Office of Integrated Analysis and Forecasting, Energy Information Administration (December). 
2005a. International Energy Outlook 2005. Washington: Office of Integrated Analysis and Forecasting, Energy Information Administration (July). . 2005b. Assumptions to the Annual Energy Outlook 2005. Washington: Office of Integrated Analysis and Forecasting, Energy Information Administration (April).

ExxonMobil. 2005. "The Outlook for Energy, A View to 2030” (exxonmobil.com/ corporate/Citizenship/Imports/EnergyOutlook05/2005_energy_outlook.pdf).

Falnes, Johannes, and Jorgen Lovseth. 1991. “Ocean Wave Energy.” Energy Policy 19, no. 8: 768-75.

Fischer, Carolyn. 2004. "Emissions Pricing, Spillovers, and Public Investment in Environmentally Friendly Technologies." Washington: Resources for the Future (February).

Goodstein, David. 2004. Out of Gas: The End of the Age of Oil. Norton.

Herzog, Howard, Baldur Eliasson, and Olav Kaarstad. 2000. "Capturing Greenhouse Gases." Scientific American no. 2: 72-79.

Hidalgo, Ignacio, and others. 2005. "Technological Prospects and $\mathrm{CO}_{2}$ Emission Trading Analyses in the Iron and Steel Industry: A Global Model.” Energy 30, no. 5: 583-610.

Hoffert, Martin I., and others. 2002. "Advanced Technology Paths to Global Climate Stability: Energy for a Greenhouse Planet.” Science 298, no. 5595: 981-87.

Houghton, John. 2001. The Physics of Atmospheres, 3rd ed. Cambridge University Press.

Houghton, John T., and others. 2001. Climate Change 2001: The Scientific Basis. Geneva: Intergovernmental Panel on Climate Change.

Howes, Ruth H., and Anthony Fainberg, eds. 1991. The Energy Sourcebook. New York: American Institute of Physics.

Hubbert, M. King. 1956. "Nuclear Energy and the Fossil Fuels." Shell Publication 95. Houston: Shell Development Company (June).

Kaneko, Takao, and others. 2002. "Coal Liquefaction.” In Ullmann's Encyclopedia of Industrial Chemistry. Wiley-VCH.

Keith, David W., and others. 2004. "The Influence of Large-Scale Wind Power on Global Climate." Proceedings of the National Academy of Sciences of the United States of America 101, no. 46: 16115-20.

Kheshgi, Haroon S. 2004. "Ocean Carbon Sink Duration under Stabilization of Atmospheric $\mathrm{CO}_{2}$ : A 1,000-Year Timescale." Geophysical Research Letters 31, no. L20204.

Kheshgi, Haroon S., and David E. Archer. 2004. "A Nonlinear Convolution Model for the Evasion of $\mathrm{CO}_{2}$ Injected into the Deep Ocean." Journal of Geophysical Research 109: C02007.

Kirk-Othmer Encyclopedia of Chemical Technology. 2000. Hoboken, N.J.: Wiley InterScience. 
Kleypas, Joan A., Robert W. Buddemeier, and Jean-Pierre Gattuso. 2001. "The Future of Coral Reefs in an Age of Global Change." International Journal of Earth Sciences 90: 426-37.

Kleypas, Joan A., and others. 1999. "Geochemical Consequences of Increased Atmospheric Carbon Dioxide on Coral Reefs." Science 284, no. 5411: 118-20.

Lackner, Klaus S. 2002. "Carbonate Chemistry for Sequestering Fossil Carbon." Annual Review of Energy and the Environment 27, no. 1: 193-232. 2003. "Climate Change: A Guide to $\mathrm{CO}_{2}$ Sequestration." Science 300, no. 5626: 1677-78.

Lackner, Klaus S., Hans-J. Ziock, and Patrick Grimes. 1999. "Carbon Dioxide Extraction from Air: Is it an Option?" In Proceedings of the 24th International Conference on Coal Utilization \& Fuel Systems, Clearwater, Florida, edited by Barbara Sakkestad. Gaithersburg, Md.: Coal Technology Association.

Langdon, Chris, and others. 2000. "Effect of Calcium Carbonate Saturation State on the Calcification Rate of an Experimental Coral Reef." Global Biochemical Cycles 14, no. 2: 639-54.

Lindzen, Richard S., Ming-Dah Chou, and Arthur Y. Hou. 2001. "Does the Earth Have an Adaptive Infrared Iris?" Bulletin of the American Meteorological Society 82, no. 3: 417-32.

Lumpkin, Robert E. 1988. "Recent Progress in the Direct Liquefaction of Coal." Science 239: 873-77.

Maddison, Angus. 2001. The World Economy: A Millennial Perspective. Paris: Development Centre of the Organization for Economic Cooperation and Development.

Metz, Bert, and others, eds. 2005. "IPCC Special Report on Carbon Dioxide Capture and Storage, Summary for Policymakers and Technical Summary." Geneva: Intergovernmental Panel on Climate Change.

Munk, Walter. 1997. "Once Again: Once Again-Tidal Friction.” Progress in Oceanography 40, nos. 1-4: 7-35.

Nakicenovic, Nebojsa, and others. 2001. "Special Report on Emission Scenarios." Geneva: Intergovernmental Panel on Climate Change.

National Commission on Energy Policy. 2004. Ending the Energy Stalemate. Washington.

National Energy Board, Canada. 2004. “Canada's Oil Sands: Opportunities and Challenges to 2015." Calgary, Alberta: National Energy Board (May).

Phillips, Oliver L., and others. 2002. "Increasing Dominance of Large Lianas in Amazonian Forests." Nature 418, no. 6899: 770-74.

Plotkin, Steven, and others. 2001. "Hybrid Electric Vehicle Technology Assessment: Methodology, Analytical Issues, and Interim Results.” Argonne, Ill.: Center for Transportation Research, Energy Systems Division, Argonne National Laboratory (October). 
Rogner, Hans-Holger. 1997. "An Assessment of World Hydrocarbon Resources." Annual Review of Energy and Environment 22: 217-62.

Schimel, David S., and others. 1995. " $\mathrm{CO}_{2}$ and the Carbon Cycle." In IPCC Special Report on Climate Change 1994: Radiative Forcing of Climate Change and an Evaluation of the IPCC IS92 Emissions Scenarios, edited by John T. Houghton and others. Cambridge University Press.

Schlesinger, William H., and Jeffrey A. Andrews. 2000. "Soil Respiration and the Global Carbon Cycle." Biogeochemistry 48, no. 1: 7-20.

Simmons, Matthew R. 2005. Twilight in the Desert: The Coming Saudi Oil Shock and the World Economy. Hoboken, N.J.: John Wiley \& Sons.

Smil, Vaclav. 2001. Enriching the Earth: Fritz Haber, Carl Bosch, and the Transformation of World Food Production. MIT Press.

Stewart, Robert H. 2005. Introduction to Physical Oceanography. College Station, Tex.: Texas A\&M University (oceanworld.tamu.edu/resources/ocng_textbook).

Steynberg, A. P., and others. 1999. "High Temperature Fischer-Tropsch Synthesis in Commercial Practice." Applied Catalysis A: General 186, no. 1: 41-54.

Tol, Richard S. J. 2005. "The Marginal Damage Costs of Carbon Dioxide Emissions: An Assessment of the Uncertainties." Energy Policy 33: 2064-74.

Uranium Committee of the American Association of Petroleum Geologists. 2005. "Recent Uranium Industry Developments, Exploration, Mining and Environmental Programs in the U.S. and Overseas." Tulsa, Okla.: American Association of Petroleum Geologists.

Worrell, Ernst, and others. 2001. "Carbon Dioxide Emissions from the Global Cement Industry." Annual Review of Energy and the Environment 26, no. 1: 303-29.

Yegulalp, Tuncel M., Klaus S. Lackner, and Hans J. Ziock. 2001. "A Review of Emerging Technologies for Sustainable Use of Coal for Power Generation." International Journal of Surface Mining, Reclamation and Environment 15, no. 1: 52-68.

Zeman, Frank S., and Klaus S. Lackner. 2004. "Capturing Carbon Dioxide Directly from the Atmosphere." World Resource Review 16, no. 2: 157-72. 